\title{
Student-Instructor Out-of-Class Communication: A Media Multiplexity Approach
}

\author{
Cathlin V. Clark-Gordon \\ West Virginia University, cvc0003@mix.wvu.edu
}

Follow this and additional works at: https://researchrepository.wvu.edu/etd

Part of the Communication Technology and New Media Commons

\section{Recommended Citation}

Clark-Gordon, Cathlin V., "Student-Instructor Out-of-Class Communication: A Media Multiplexity Approach" (2019). Graduate Theses, Dissertations, and Problem Reports. 3798.

https://researchrepository.wvu.edu/etd/3798

This Dissertation is protected by copyright and/or related rights. It has been brought to you by the The Research Repository @ WVU with permission from the rights-holder(s). You are free to use this Dissertation in any way that is permitted by the copyright and related rights legislation that applies to your use. For other uses you must obtain permission from the rights-holder(s) directly, unless additional rights are indicated by a Creative Commons license in the record and/ or on the work itself. This Dissertation has been accepted for inclusion in WVU Graduate Theses, Dissertations, and Problem Reports collection by an authorized administrator of The Research Repository @ WVU.

For more information, please contact researchrepository@mail.wvu.edu. 
Student-Instructor Out-of-Class Communication: A Media Multiplexity Approach

\author{
Cathlin V. Clark-Gordon
}

Dissertation submitted to the Eberly College of Arts and Sciences at West Virginia University

in partial fulfillment of the requirements for the degree of

\author{
Doctor of Philosophy \\ in Communication Studies
}

Nicholas David Bowman, Ph.D., Chair

Alan K. Goodboy, Ph.D.

Elizabeth L. Cohen, Ph.D.

Liesel L. Sharabi, Ph.D.

Andrew M. Ledbetter, Ph.D.

Department of Communication Studies

Morgantown, West Virginia

2019

Keywords: Media Multiplexity Theory, Out-of-Class Communication, Instructor-Student Relationship, Mixed-Mode Relationships

Copyright 2019 Cathlin V. Clark-Gordon 


\section{ABSTRACT \\ Student-Instructor Out-of-Class Communication: A Media Multiplexity Approach}

\section{Cathlin V. Clark-Gordon}

The present set of studies examined media multiplexity theory (MMT; Haythornthwaite, 2005) in the context of student-instructor out-of-class communication (OCC) in two samples: undergraduate and graduate students. It was predicted that student-instructor tie strength (closeness) would lead to a greater number of modes used for OCC, and subsequently, the number of modes used for OCC would predict positive classroom outcomes, including communication satisfaction, cognitive and affective learning, and motivation. It was also predicted that the effect of closeness on the number of modes used for OCC would be moderated by student's enjoyment of online communication, insofar as it would suppress the amount of modes used to communicate outside the classroom for those students who did not enjoy online communication, or amplify the effects for those students that did enjoy online communication.

Results revealed that for undergraduate students, the number of media used to communicate with one's instructor indirectly impacted their communication satisfaction, affective and cognitive learning, and motivation, through their feelings of the closeness with their instructor, contrary to the hypothesized model. This effect was strengthened for those students who had greater enjoyment of online communication. For graduate, the same pattern of indirect effects emerged, but enjoyment of online communication had no moderating effect in the graduate student sample. Implications for Media Multiplexity Theory (MMT) and viewing the student-instructor relationship as interpersonal are discussed. Because MMT was supported by the present studies, important conclusions on the nature of the student-instructor relationship, and the subsequent effects of their communication patterns are drawn. 
Table of Contents

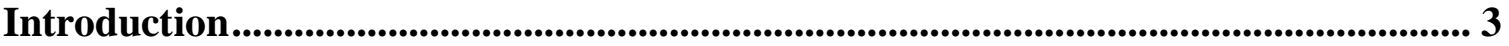

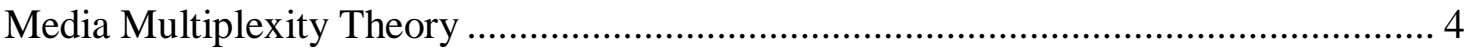

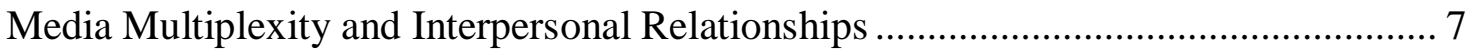

Student-Instructor Interactions as Interpersonal Communication............................... 9

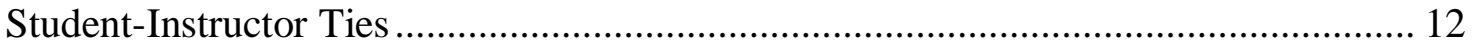

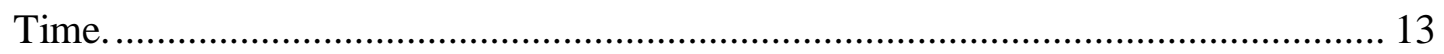

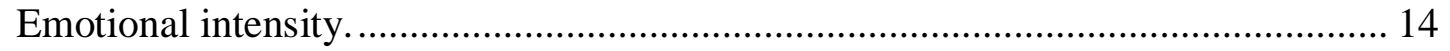

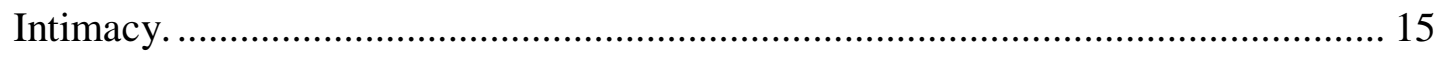

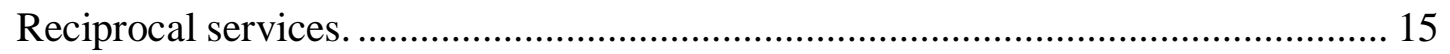

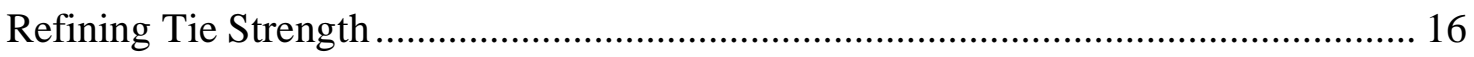

Student-Instructor Interactions as OCC …......................................................... 18

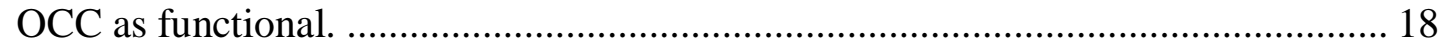

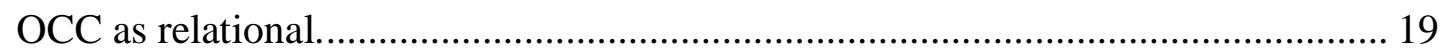

Online Communication Attitudes Drive Modality Choices ..................................... 21

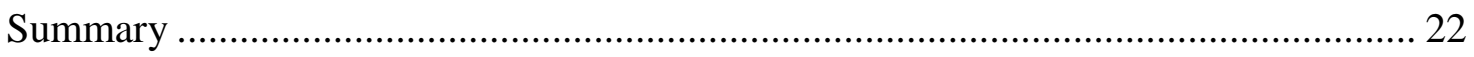

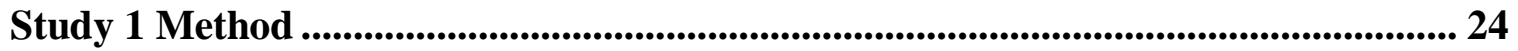

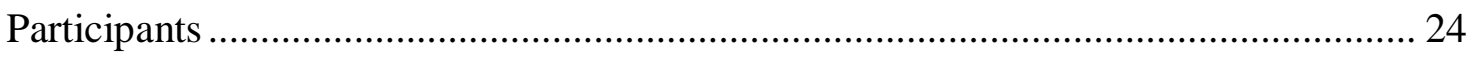

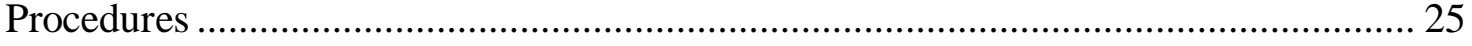

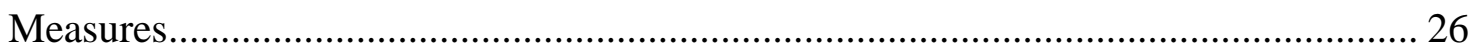

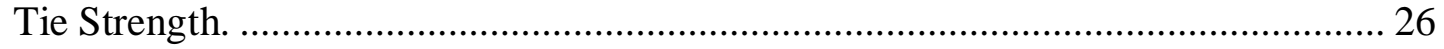

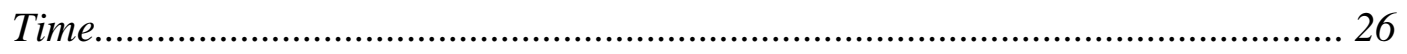

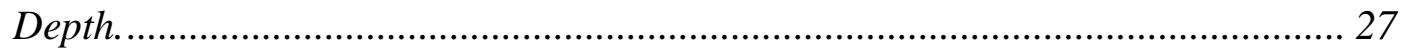

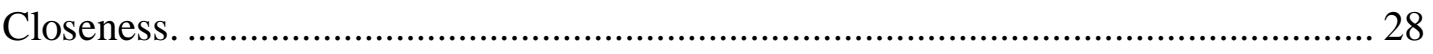

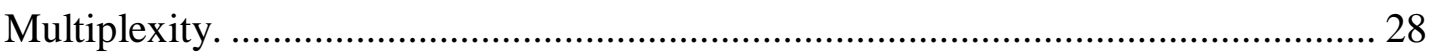

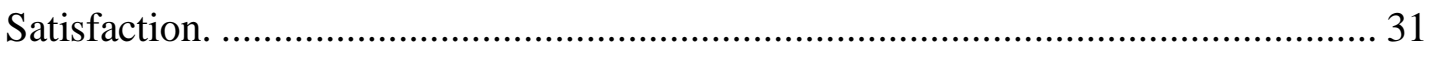

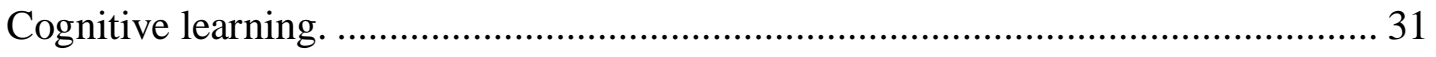

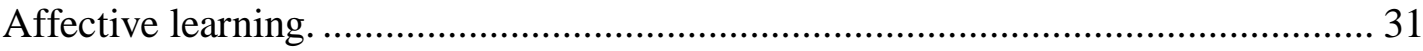

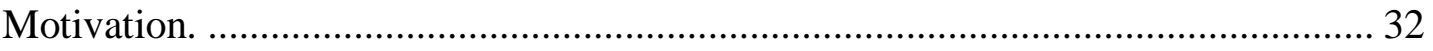

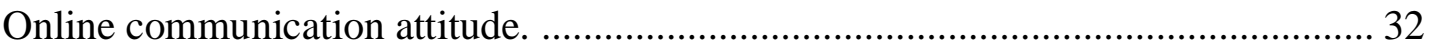

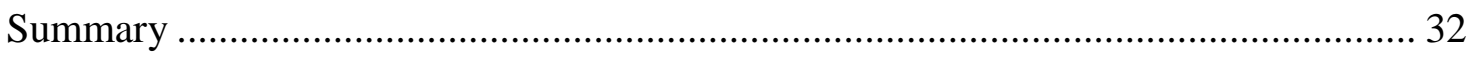

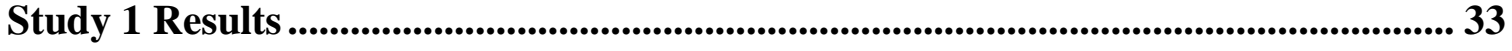

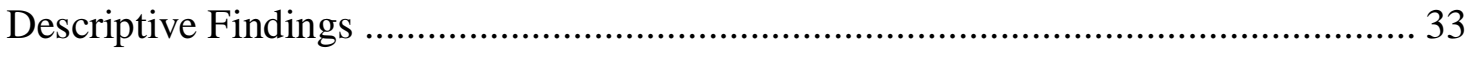

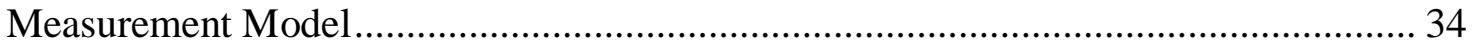

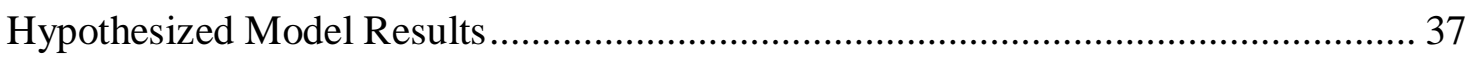

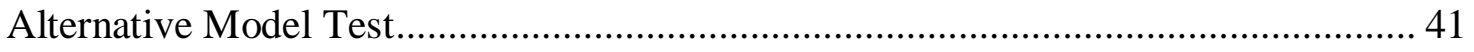

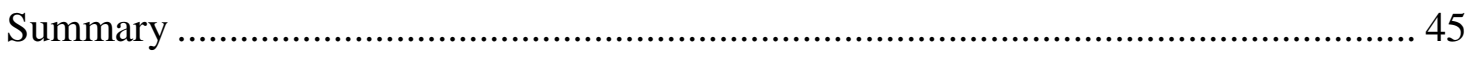


Study 2 Method ..................................................................................................................................... 45

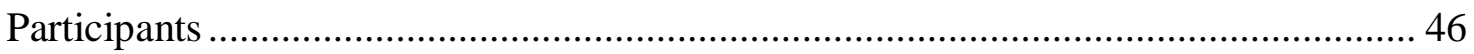

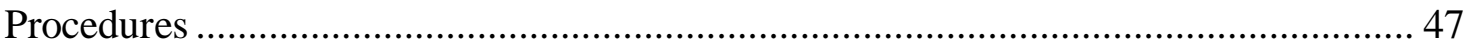

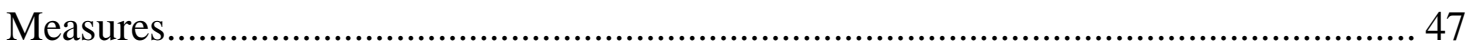

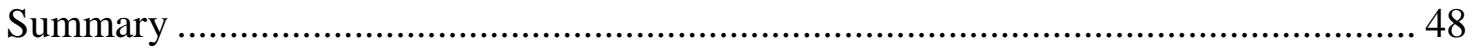

Study 2 Results

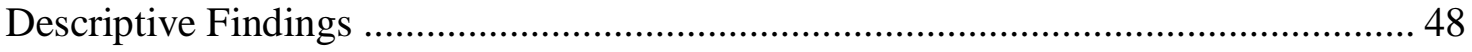

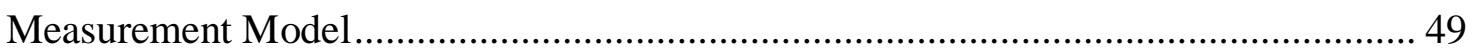

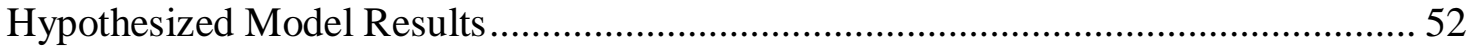

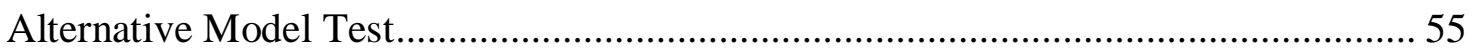

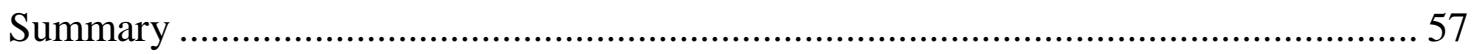

Discussion .......................................................................................................................................... 58

The Instructor-Student Relationship: Interpersonal or Task Orientation? .................... 59

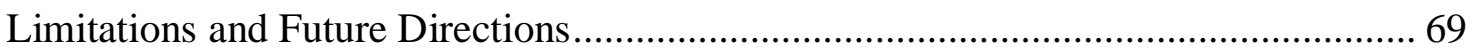

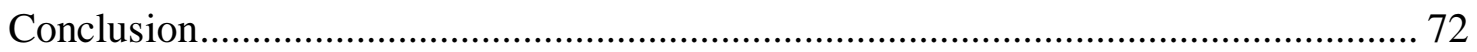

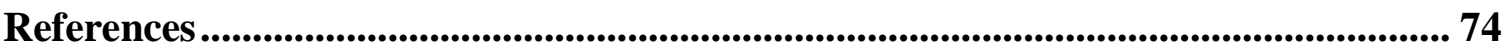




\section{List of Figures}

Figure 1. Conceptual Model..................................................................................... 23

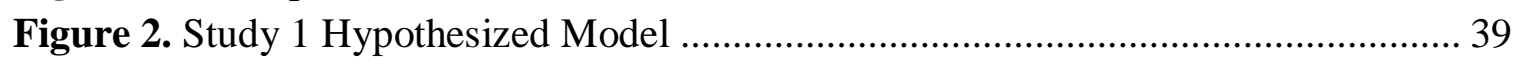

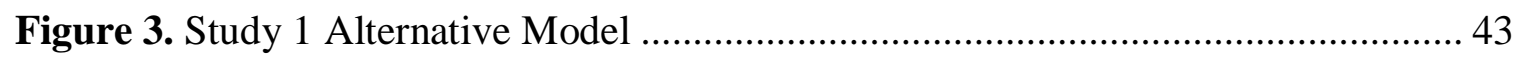

Figure 4. Study 2 Hypothesized Model ................................................................ 53

Figure 5. Study 2 Comperting Model ...................................................................... 56 


\section{List of Tables}

Table 1. Frequency of Modality Occurance in Student-Instructor Communication ....... 29

Table 2. Modalities Used as Response Options in Previous MMT and OCC Research.. 30

Table 3. Study 1 Modality Usage Descriptive Statistics .............................................. 33

Table 4. Study 1 Measurement Model ..................................................................... 35

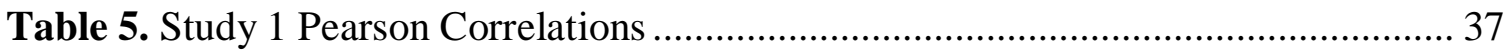

Table 6. Study 1 Conditional Indirect Effects for Hypothesized Model......................... 40

Table 7. Study 1 Conditional Indirect Effects for Alternative Model ............................. 44

Table 8. Study 2 Modality Usage Descriptive Statistics .............................................. 49

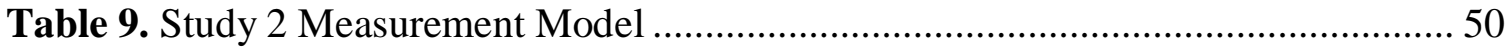

Table 10. Study 2 Pearson Correlations ....................................................................... 52

Table 11. Study 2 Conditional Indirect Effects for Hypothesized Model....................... 54

Table 12. Study 2 Conditional Indirect Effects for Alternative Model........................... 57 


\section{List of Appendices}

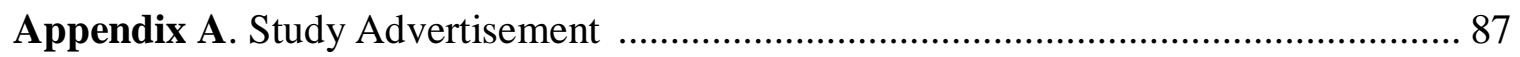

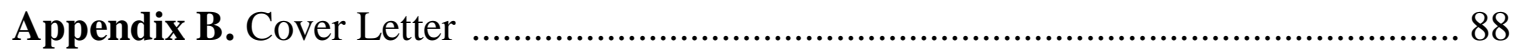

Appendix C. Measures for Survey Instrument ……….............................................. 90 


\section{DEDICATION}

I would like to dedicate this dissertation to my late father, Frederick Keith Clark. My dad passed away near the end of my first year of my doctoral studies, and I am writing this dedication to him just two years after his passing. He was my number one supporter, the greatest coach, and one of my closest friends. Knowing that he would want me to succeed is what kept me going on the many days when I felt like I wanted to give up. As poet T.S. Eliot said, "If you aren't in over your head, how do you know how tall you are?" Thanks to you, Dad, I continue to stand tall. 


\section{ACKNOWLEDGEMENTS}

First and foremost, I would like to acknowledge and thank my advisor, chair, and mentor, Dr. Nick Bowman. This project would not exist without his outstanding leadership, guidance, and expertise. The opportunities and challenges this project presented, under the guidance of Dr. Bowman, have served to spark my professional and personal growth.

I would like to extend my gratitude to my committee members, Drs. Alan Goodboy, Elizabeth Cohen, Liesel Sharabi, and Andrew Ledbetter, for their expertise, time, and tireless assistance.

I would also like to thank my cohort, including my conference gals Sara and James, for their immeasurable support and camaraderie throughout our time in the program. Without the friendships and culture of support we created, the challenges of doc school would have been much more daunting.

I could never have been successful without the constant encouragement from my husband. Any house would crumble without a solid foundation, and for being my rock throughout graduate school I owe him the world. And lastly, I would like to thank my Mom, my sister, and my brother for being my cheer squad during this process. You all always said I could do it, even on days when I didn't believe you. Thank you all for believing in me. 


\section{CHAPTER 1}

Introduction

Rapid development and implementation of digital technology is a ubiquitous theme across educational settings. In K-12 settings, public schools in the United States now provide at least one computer for every five students and spend more than $\$ 3$ billion per year on digital content (Herold, 2016). The modern college classroom, of course, is impacted by this technology. Teachers and professors are incorporating more technology into their lecture materials by using devices like iClickers or polling apps for smartphones (Mohr, 2013). Many classrooms are "smart" and have enhanced capabilities for presentations, moving beyond the capabilities of PowerPoint. Literature has also addressed the negative potentials of technologies in the classroom, investigating the role of texting or other smartphone usage by students. Some consider student use of smartphones during class to be multitasking (i.e., Junco, 2015; Xu, Wang, \& David, 2016) while others suggest that smartphones are a distraction and deter from learning and achievement in the classroom (i.e., Kuznekoff \& Titsworth, 2013). While these technologies may seem omnipresent in the classroom, it is also likely that instructors and students use technology to communicate outside of the classroom.

The bulk of scholarly attention has been on the effects of student technology use in the face-to-face $(\mathrm{FtF})$ classroom, and the perceptions of technology during online learning and distance education. The college classroom does not exist in only one space. Students regularly have to complete reading, activities, and homework outside of the classroom. Many professors also choose to move toward a hybrid classroom or even a flipped classroom, where lecture material is delivered online and activities are done 
together in the traditional classroom to individualize attention to students (Bishop \& Verleger, 2013). Further, students need to communicate with their professors, and professors need to communicate individually with students - and this communication does not always happen during scheduled instructional time. While the majority of scholarly attention has been focused on how advances in technologies may help or hinder in-class instruction, this study focuses on the potential of technology to also impact outof-class instruction and relationships. Given recent growth in communication technologies, there still exists a gap in the literature that examines how using a variety of communication channels, including smartphones and classroom technologies, might impact student and professor communication outside of the classroom. Through the lens of media multiplexity theory (Haythornthwaite, 2005), this study proposes to investigate the ways in which students and instructors communicate outside the confines of the classroom, and explores if using multiple modes of student-instructor communication play a role in students' communication satisfaction and academic achievement.

\section{Media Multiplexity Theory}

Interpersonal partners frequently use more than one channel (or medium) to communicate, a phenomenon known as multimodality (i.e., Walther \& Parks, 2002). When conversation partners engage in multimodal communication, they use different channels to communicate with one another, either synchronously or asynchronously. Interactants may integrate modes of communication (extending discussions back and forth between mediated interactions and in-person conversations), or they may experience mode segmentation, where they only feel comfortable discussing certain issues via one mode of communication (Caughlin \& Sharabi, 2013). An approach that 
considers all modes used to communicate holistically is called media multiplexity theory (MMT; Haythornthwaite, 2005). Media multiplexity theory (MMT) predicts that stronger ties use more media channels to communicate than do weak ties (Haythornthwaite, 2005). Ties, as outlined by Granovetter (1973), represent the strength of a relationship between two individuals (a dyad) in sociometry and social network analysis. More practically, the relative 'strength' of ties (two connected individuals) is representative of the types of relationship they characterize. The types of relationships demonstrated by weak ties are generally acquaintances and casual contacts, while more strongly tied pairs might be friends, family members, coworkers, or romantic partners (Granovetter, 1973; Haythornthwaite, 2005). Haythornthwaite's (2005) work explored what type of relationships made up both organizational and distance learning ties, and further investigated these ties' patterns of media usage in two studies. Haythornthwaite (2005) took a social network approach to studying the strength and connection between ties, and was interested in asking members of groups who talks to whom, about what, and via which media. Her work suggests that stronger ties do use more media channels to communicate, but what is communicated does not differ by media, but instead by the type of tie. Strong ties were more likely to communicate about socializing and emotional support, while weak ties were more likely to communicate about collaborating on classwork and exchanging information or advice regarding classwork. Haythornthwaite used indicators of tie strength including: the amount of communication between the dyad, maintenance of a greater number of relations (relational multiplexity), and of relations that include emotional and social support. Essentially, by asking "who talks to whom about what via which [and how many] media" (expanding upon the work of Lasswell, 
1948), she found that as tie strength increased, so did the number of modes used to communicate. For example, with a strong tie, communication may occur through textmessaging, IM, voice calls, video calls, and social media, while for a weak tie communication may only occur through email and text messages.

Haythornthwaite's (2005) work with distance learners enrolled in an online class, mentioned above, suggest that two social network patterns exist: wide connectivity (many connected weak ties with relatively low communication) and a second pattern of selective connectivity with those in close work or social ties, characterized by higher frequency of communication and use of person-to-person, private, and optional means of communication. Specifically, through her network analysis of all ties enrolled in the online class, she found support for wide connectivity through the class-mandated media (such as discussion boards), but closely tied pairs of individuals supported the selective connectivity pattern with email, phone, and private instant messaging. Practically, for studying media multiplexity, these findings suggest that new information was passed through many sets of weak ties through public channels, while help in task completion and socializing, for those who work together, were communicated via private media. This suggests that stronger ties use more, and different, media than do weak ties. In the context of the classroom, this research shows that mandated use of communication technologies (i.e., those required by the instructor) will greatly influence communication patterns, affecting both who communicated more with others (because of partner or group assignments) and what media were used to communicate (if online discussion boards or blog postings were graded). However, Haythornthwaite's work with distance learners only focused on the communication patterns between the learners (i.e., students) 
themselves, and not on patterns that existed with the instructor of the course, or those communication patterns that happened outside the confines of the class, making this an area worthy of further exploration.

\section{Media Multiplexity and Interpersonal Relationships}

Additional research on media multiplexity suggests that the communication patterns for weak and strong ties outlined by MMT hold together across different types of relationships (such as friendships or between romantic partners) and for different levels of analysis (using individual or dyadic data rather than the network perspective used by Haythornthwaite, 2005). MMT, as applied to interpersonal relationships, would suggest that those in earlier stages of relational development use fewer communication channels, but as relationships developed, more channels would be used. Additionally, as the number of channels used between interactants grows, channels used to communicate in earlier interactions are retained to communicate in later interactions, even after the relationship has continued to develop (and the ties have become stronger; i.e. Sharabi \& Caughlin, 2017).

Tie strength in interpersonal relationships has been shown to predict the modes used to communicate, and the frequency of channel usage. Within the context of interpersonal relationships, tie strength is frequently operationalized as interdependence, or the mutual reliance between any two individuals (a tie). Ledbetter and Mazer (2014) found that Facebook communication was positively associated with relational interdependence, but only for participants who had positive attitudes toward selfdisclosure and social connection online. This extended the work of Baym and Ledbetter (2009) who found that connectivity on the music-based social networking site Last.fm 
also lead to perceived interdependence. Maintaining relationships via modes such as Xbox LIVE, when combined with offline communication frequency, have been shown to interact to predict relational closeness (Ledbetter \& Kuznekoff, 2012). Miczo, Mariani, and Donahue (2011) researched media multiplexity in the context of friendship maintenance, finding that number of channels was related to solidarity in friendships. Further, Ledbetter (2009b) investigated the extent to which different media types (media multiplexity) have an additive or a multiplicative effect on interdependence, finding that media multiplexity has an additive effect (i.e., each media type contributes to variance in interdependence), rather than the media having an interaction (multiplicative) effect on relational interdependence.

Caughlin and Sharabi (2013) also argue that media multiplexity involves interdependence, but rather than conceptualizing this interdependence as relational, they argue for communicative interdependence. Communicative interdependence was developed as a way to go beyond measuring the number of modes used by interactants, and recognizes that people tend to use multiple modes of communication in close relationships, so it is also important to understand how the use of those modes are interconnected. They argue that interdependence is not merely a global sense of being connected to another person, it is also reflected in the interpersonal behaviors within relationships - arguing the importance of understanding how relational behaviors are connected. Translated to the student-instructor relationship, relational communication behaviors are likely interconnected due to the structure of the course, the nature of the relationship, and the content being communicated. For example, instructors communicate content expertise to students, and students may be required to participate in class, and 
turn in various assignments. When the instructor provides feedback on these assignments, perhaps via a different mode than they deliver the class content in (i.e. lecturing face-toface but providing feedback in an email), these interdependent behaviors likely increase the multiplexity of channels used to communicate between the instructor and the student.

\section{Student-Instructor Interactions as Interpersonal Communication}

Frymier and Houser (2000) argue that the relationship between the instructor and the student is inherently interpersonal. Student-instructor relationships follow many of the same patterns as other types of relationships, such as developing through relative intimacy, to eventual dissolution at a semester's end or graduation date. Additionally, both students and instructors have goals they wish to achieve in the context of a classroom, and these goals must be negotiated and sometimes, involve conflict resolution among the instructor and the student. This pattern also exists for superior-subordinate communication in the context of organizational communication, and for the coach-athlete relationship in the context of sport communication, to provide two examples for types of interpersonal relationships that have been studied more extensively. Research suggests that superiors and subordinates need to maintain their interpersonal relationship in strategic situations, using tactics and strategies that differ from maintenance in other types of interpersonal relationships (particularly romantic relationships; Lee \& Jablin, 1995). Work of Jowett $(2003,2007)$ suggests that coaches and athletes go through crises and conflicts throughout a given sports' season, and that the coach-athlete relationship is ultimately interdependent (including the pairs closeness, commitment, complementarity, and co-orientation). While the conditions under which the student-instructor relationships differ from those of other relationships (student-instructor relationships 
have a power distance and a potentially limited lifespan), there are enough similarities to warrant further exploration of interpersonal outcomes associated with this relationship, such as the formation, maintenance, and dissolution, the need for conflict management, and potential for greater closeness and intimacy over time. Wubbels and Brekelmans (2005) developed a model to describe teacher-student relationships. Their Model for Teacher Interpersonal Behavior (MTIB) claims that teacher-student interpersonal relationships are necessary for high-achievement in students, which are characterized by a teacher's influence and proximity towards students. Nonverbal behavior and the spatial position of the teacher in the class support the need for beginning teachers to portray the image of an experienced teacher whenever they address the class as a group. Likewise, Anderson and Carta-Falsa (2002) identified factors that make faculty and student interpersonal relationships effective. A qualitative analysis of narratives describing what students and faculty wanted in their relationships found that both students and faculty desire nurturing, open, non-threatening, and respectful communication in student-faculty relationships.

Another way of considering the student-instructor interpersonal relationship is by their rapport. Rapport is an overall feeling between two people encompassing a mutual, trusting, and prosocial bond (i.e., Catt, Miller, \& Schallenkamp, 2007). Rapport has been argued to be one variable that is able to truly capture the nature of the interpersonal relationship between instructors and students (Frisby \& Martin, 2010; Jorgenson, 1992). Thus, rapport may enhance perceptions of an interpersonal relationship in the classroom. Frisby and Martin (2010) studied student-instructor rapport, finding that perceived rapport with instructors is positively related to perceptions of classroom connectedness, 
and that instructor rapport is positively associated with participation, affective learning, and cognitive learning.

Further, and potentially most importantly for taking a media multiplexity approach to student-instructor relationships, Dobransky and Frymier (2004) found that students who engage in out-of-class communication (OCC) with their instructors have relationships that are more interpersonal in nature than students who do not engage in OCC. The researchers argued that the core dimensions of interpersonal relationships are control, trust, and intimacy, and that these variable can also map onto the relationship experienced between instructors and students (Dobransky \& Frymier, 2004). To this point, Dobransky and Frymier found that students who perceived their teachers as exhibiting higher levels of shared control, trust, and intimacy, self-reported greater learning in class.

However, there are challenges associated with viewing the student-instructor relationship as inherently interpersonal in nature. First, there is a power distance between students and instructors. Teachers are responsible for students' course grades, and students must submit assignments, tests, and other work to earn their course grade. Grading policies may vary by instructor, with some adopting transparent techniques such as rubrics, while others may use grading systems that are unknown to students. Second, there is an element of exchange of services associated with the college classroom. Students pay to be enrolled in their courses, and expect educational services, and ostensibly, learning, in return. Third, and likely most important in its implications for MMT, is that instructors may instate mandatory modes of communication both in- and out-of-class. That is, students may not be able to choose all of the modes they 
communicate with their professors or may have limited choices due to instructor policies.

For these reasons, there must be distinctions between other types of interpersonal relationships and those that are specific to the student-instructor context.

While the student-instructor relationship does not have the same conventions and markers as other types of interpersonal relationships (i.e., friendships, romantic relationships, etc.), research suggests that there are enough similarities to consider it a type of interpersonal relationship. Students can experience rapport with their instructor (Frisby \& Martin, 2010), and just like other types of interpersonal relationships, greater communication between instructors and students leads to relational development through the perceptions of heightened control, trust, and intimacy (i.e., Dobransky \& Frymier, 2004). In Hattie's (2009) synthesis of meta-analyses related to student achievement, he found that the average effect of 229 studies examining the effect of the teacher-student relationship on student achievement was $d=.72$, suggesting that the students' perception of their relational quality with their instructor was a major contributor to their overall achievement. Above all, this research suggests that greater communication between relational partners leads to positive perceptions of the partner and greater relational outcomes. However, it does not explore how different modes of communication impact relational perceptions in this context, a gap in the literature that could be informed with interpersonal theories of multimodality.

\section{Student-Instructor Ties}

One key connection between strands of multimodality research is that they rely on tie strength. While this has been operationalized in different ways (indicators used by Granovetter, 1973 as well as Marsden and Campbell, 1984 including time and depth; 
measures of closeness used by Ruppel and Burke, 2014, and Ruppel, Burke, and Cherney, 2018, measures of interdependence used by Ledbetter, 2009b; Ledbetter \& Mazer, 2014), tie strength plays a key role in this line of research. A weak tie is akin to an acquaintance, and the strongest of ties are the closest of friends. Although perhaps student-instructor relationships will never blossom into a closely knit friendship, there is opportunity for variation on the continuum between strong and weak ties. If a weak tie is only really an acquaintance, by the end of an academic semester, it is likely that the tie strength between an instructor and a student has become stronger. However, unlike the student-student relationships studied by Haythornthwaite (2005) and the friendships studied by Ledbetter (2009b), the student-instructor relationship introduces the element of a power structure. Because the instructor is ultimately responsible for a student's performance evaluations and grades, there is potential that the students are more dependent on their instructors than instructors are on students. While this may vary for graduate students (who may have a more interdependent relationship with their professors because of research and writing responsibilities), there is ultimately a power distance between professors and students of all kinds. Granovetter's (1973) four criteria that determine interpersonal tie strength are time, emotional intensity, intimacy, and reciprocal services. Because tie strength is core to MMT's prediction (that stronger ties use more media channels to communicate), an argument can be made that the studentinstructor relationship can meet all four criteria offered by Granovetter, allowing this type of relationship to vary in strength.

Time. Ties will become stronger the more time that is spent together (Granovetter, 1973). In the case of the student-instructor relationship, this would happen 
naturally over the course of a semester as time spent in class increases. Theories of computer-mediated communication (CMC) also predict that given sufficient time, mediated relationships can develop to the same level of intimacy as face-to-face relationships (Walther, 1992). Therefore, regardless if the student is enrolled in a face-toface, online, or hybrid course, over time their tie strength will increase. According to the predictions of MMT, as the tie strength increases, so would the number of modes the instructor and student use to communicate. Additional modes may be more native to the design of a hybrid course, which involves both face-to-face and online components, which may give some students and instructors an advantage to approach communication through multiple modes.

Emotional intensity. Ties become stronger as emotions become more intense (with romantic partners these emotions would differ than those felt among close friends, etc.; Granovetter, 1973) Emotions are often felt by students in the classroom both towards the instructor and towards the content (i.e., Titsworth, Quinlan, \& Mazer, 2010), and have the potential to intensify over the course of a semester. Mazer (2017) found that students who experienced enjoyment, hope, and pride in a class report not only being engaged (including students' out-of-class behaviors), but also being cognitively and emotionally interested in the course. On the other hand, students who experienced anger, anxiety, shame, hopelessness, and boredom reported being less engaged and expressed less interest in the course. Moreover, the extent to which students perceive that they receive emotional support from their instructors is predicted positively by their feelings of enjoyment, hope, and pride, but is predicted negatively by their feelings of anger, anxiety, shame, hopelessness, and boredom (Mazer, McKenna-Buchanan, Quinlan, \& 
Titsworth, 2014; Titsworth, McKenna, Mazer, \& Quinlan, 2013). Therefore, receiving increased emotional support from an instructor is also likely to contribute to an increase in their tie strength, as well as other beneficial outcomes in the classroom.

Intimacy. Intimacy is often defined as feelings of closeness and connection between two individuals (Wood, 2002). While it has been argued that intimacy is inappropriate in the context of the student-instructor relationship (McCroskey, 1992), others argue that the sense of platonic closeness in student-instructor relationship is experienced differently than romantic intimacy among close partners (Dobransky \& Frymier, 2004). Dobransky and Frymier (2004) found that intimacy enhances learning and motivation. Claus, Booth-Butterfield, and Chory (2012) found that closeness was negatively related to the likelihood of students communicating antisocially. Therefore, perceptions of intimacy or relational closeness in student-instructor relationships are likely to predict communication.

Reciprocal services. Reciprocal services are characteristic of the type of tie/relationship, and would differ among types of ties (i.e., romantic partners and coworkers would not do the same acts of service for one another; Granovetter, 1973). Classroom citizenship behaviors (Myers et al., 2016) are an emerging area of research in instructional communication, which suggest reciprocal services happen within the classroom. Myers et al. (2016) identified classroom citizenship behaviors (CCB) as students' voluntary engagement in behaviors that promote the functioning of the classroom and instruction, and include the dimensions of involvement, affiliation, and courtesy. Involvement refers to student behaviors focused toward the instructor that students use to engage and interact during class, affiliation refers to student behaviors 
focused on classmates in order to connect and collaborate, and courtesy refers to student behaviors that are directed toward the classroom environment and represent instructional etiquette. Myers and colleagues (2016) found that CCBs are associated positively with students' perception of the classroom environment (i.e., supportive classroom climate, connectedness, and rapport), their emotional and cognitive interest, and their reports of affective learning, cognitive learning, state motivation, and communication satisfaction. Outside of CCBs, there are other reciprocal services native to the student-instructor relationship, particularly given the financial exchange that is required for higher education. Students are required to pay for their credit hours and courses, and therefore expect some type of educational gains in return. Instructors share their knowledge and content expertise with students, but also expect students to return graded assignments, take tests, etc. Therefore, the reciprocal services in the student-instructor tie are likely very different from other connections (particularly those in strong tie relationships).

\section{Refining Tie Strength}

Work of Marsden and Campbell $(1984 ; 2012)$ tested and expanded upon the work of Granovetter (1973). They argue that there are both indicators of tie strength (which actually help with measuring the unobserved variable) and predictors of tie strength (which describe conditions that lead to stronger ties, but are not actually indicators of tie strength as a latent construct). In Marsden and Campbell's (1984) work, they suggest that the four indicators suggested by Granovetter (time, emotional intensity, mutual confiding, and reciprocal services) actually factor into two distinct dimensions of tie strength: time and depth. They find that closeness and duration/frequency of contact make up the dimension of time, while the number of topics covered constitute the depth dimension. 
Their 2012 work corroborates that, despite generational changes in relationships and advances in statistical software since their initial 1984 article, "time" and "depth" are still separate, but correlated, aspects of tie strength. While Granovetter (1973) categorizes types of ties into "strong," "weak," and "absent," for the present study, a more helpful way to conceptualize tie strength may be to view tie strength as a continuous rather than a categorical variable. In particular, for the student-instructor relationship, there is potential to move through all three categories. Before the semester begins, a student-instructor tie may be absent, once it begins it becomes weak, and depending on the nature of the class and the relational development processes conceptualized for tie strength (i.e., time and depth; Marsden \& Campbell, 2012) eventually instructors and students could become intermediate to strong ties. Therefore, a continuous measure may be better-suited to understanding gradations of relational closeness, rather than using categorical indicators.

While Granovetter developed his perspective on social networks before the time of what are known as social networking sites (SNS) today, Haythornthwaite (2005) draws parallels between tie strength and technologically-mediated communication, and studies the strength of ties maintained by pairs that "can range from weak to strong according to the types of exchanges, frequency of contact, intimacy, duration of the relationship," (p. 127), falling along the dimensions of time (frequency and duration) and depth (types of exchanges) suggested by Marsden and Campbell (1984). Using this approach, Haythornthwaite's MMT could also be applied to the context of the student-instructor relationship. As it is highly likely for students to communicate with an instructor through various channels (face-to-face, email, through learning management systems, over the phone) during the semester, and develop stronger tie strength, this study proposes that 
these channels be examined in an additive way, rather than comparing one channel to another as done in past research.

\section{Student-Instructor Interactions as OCC}

Out-of-class communication (OCC) is any formal or informal interaction among students and instructors that extend past the confines of the scheduled class time (Fusani, 1994). These interactions can take the form of conversations before and after class, mediated interactions, office hour visits, and informal/formal campus meetings. Jaasma and Koper (2001) identified that students discuss course-related topics, self-disclose, engage in small talk, seek advice, share intellectual ideas, and/or solicit favors when participating in OCC. Therefore, OCC can be both functional (when it is about coursework or intellectual ideas) but also relational (when self-disclosing or seeking advice).

OCC as functional. The number one reason that students consistently identify for communicating with their instructors outside of class is to discuss course-related topics (Aylor \& Oppliger, 2003; Fusani, 1994), which is mainly done through email or during instructor office hours (Williams \& Frymier, 2007). Instructors that are perceived as responsive, supportive, and empathetic in the classroom are more likely have students visit them outside of the designated classroom time (Aylor \& Oppliger, 2003; Fusani, 1994; Nadler \& Nadler, 2000). Young, Kelsey, and Lancaster (2011) found that when students email teachers for procedural clarification reasons (i.e., to ask teachers for course/task direction, guidance, information, and feedback), students are more likely to value developing a student-teacher relationship. A meta-analysis on the effects of OCC and learning revealed positive summary effects for OCC on affective learning $(r=.321, p$ 
$<.001)$ and perceived cognitive learning $(r=.261, p<.001$; Goldman, Goodboy, \& Bolkan, 2016).

One area of OCC that is common for student-instructor communication is feedback regarding student performance in a course or on specific assignments. Instructional feedback, broadly defined, is any communicative act that an instructor engages in with a student regarding his/her performance (De Kleijn, Meijer, Pilot, \& Brekelmans, 2014). Feedback can be considered a form of OCC when discussed in office hours, in email, in online learning management systems, or in online storage systems such as Google docs or Dropbox, or any combination of these channels. Effectively communicating feedback to students has been shown to increase their motivation in the classroom (Kerssen-Griep, Hess, \& Trees, 2003). Data from Clark-Gordon, Bowman, Hadden, \& Frisby (2019) demonstrated that while the majority of professors use digital written feedback for OCC with students, they actually preferred in-class and office hours to provide students with OCC more than giving them digital feedback. Instructors reported the greatest benefit of digital written feedback was its ease of use and convenience, as well as its accessibility to both them and students. However, their biggest worry was that students were only perceiving the feedback as task communication - that they may just blindly accept changes without thinking them through or responding to the instructor. This demonstrates a desire (from the instructor's perspective) for communication between instructors and students to also be relational in nature.

OCC as relational. OCC also includes informal student-teacher contact, which is thought to effect positive outcomes in college students, such as helping them choose career paths, increasing their satisfaction with college, and aiding their intellectual and 
personal development (Pascarella, 1980). OCC has been shown to lead to academic and cognitive gains/development (Terenzini, Pascarella, \& Blimling, 1996), affect toward an instructor (Knapp \& Martin, 2002), as well as growth in interpersonal competence (Kuh, 1995) and relational development (Young et al., 2011). Bippus, Kearney, Plax, and Brooks (2003) found that an instructor's social accessibility was a significant predictor of student's positive predicted outcome value of OCC interactions. That is, students thought that communicating with instructors outside of class who seemed approachable, and were not rushed or distracted when talking with students, were more likely to lead to reward and beneficial outcomes. Further, Faranda (2015) found that when instructors' earned students' trust, it led to greater amounts of OCC between students and instructors. Myers, Martin, and Knapp (2005) found that instructor use of affinity-seeking strategies (i.e., sensitivity, self-inclusion, inclusion of others, comfortable self, and supportiveness) in class led to greater student OCC.

Taking past research on OCC into consideration, it is clear that while OCC can be used for multiple purposes, it is also conducted through multiple channels. Williams and Frymier (2007) suggested that the most frequently occurring channels for OCC are email and office hours. To expand on these findings, it is important to consider how all channels used for OCC impact the student holistically. Under the predictions of MMT, as tie strength increases, so does the number of media channels used to communicate. Extending these predictions to the context of the student-instructor relationship, as tie strength increases between the student and the instructor, so should the number of media channels used for OCC.

H1: Student-instructor tie strength will positively predict the number of media 
channels used for OCC.

Moreover, previous research suggests that participating in more OCC results in greater learning and relational outcomes for students (i.e., Pascarella, 1980; Young et al., 2011). Specifically, by combining both functional and relational OCC, students experience greater satisfaction with communication (Aylor \& Oppliger, 2003), greater cognitive and affective learning (Goldman et al., 2016), and greater motivation (Jaasma \& Koper, 1999; Kerssen-Griep et al., 2003). Therefore, it is predicted that these findings will replicate when additively considering channels used for student-instructor OCC.

H2: The number of media channels used for student-instructor OCC will positively predict student (a) communication satisfaction, (b) cognitive learning, (c) affective learning, and (d) motivation.

\section{Online Communication Attitudes Drive Modality Choices}

Further work has been done by Ledbetter and Mazer (2014) to extend MMT. Ledbetter and Mazer (2014) argue that attitudes arise from previous experiences with technology, including those direct experiences and those learned by observing others. Online communication attitudes are cognitive and affective constructions that likely influence one's propensity to engage some media channels over others. Their data suggest that strong ties employ communication channels for which they hold the mutually strongest positive attitudes. Positive attitudes toward a medium, then, predict the likelihood of using that medium to communicate in strong tie relationships. Ledbetter and Kuznekoff (2012) corroborate this claim by finding attitudes toward online social connection, or dispositions towards engaging in these sort of behaviors online, and selfdisclosure interacted to predicted Xbox LIVE relational maintenance. 
Further, Taylor, Ledbetter, and Mazer (2017) argue for a theory of medium enjoyment, where individuals' attitudes shape their use of a medium, and their desire to self-disclose or socially connect are conceptualized as different forms of enjoyment. In combining both technologically and socially oriented theories, they frame media use as an individuals' desire for enjoyable media experiences, which can be limited by the potentially competing desire for communication goal achievement. Similarly, Haythornthwaite's (2005) work with distance learners found mandated use of media by an instructor greatly influences media use patterns. Taking media enjoyment theory (MET) under consideration with Haythornthwaite's (2005) work, some use of media to communicate could be required in the context on the student-instructor relationship, a student's attitude toward communicating via certain media could not affect the number of modes used to communicate in their relationship. This research on online communication attitude, then, can be replicated and extended into the context of the student-instructor relationship.

H3: Online communication attitude will moderate the relationship between tie strength and number of channels used to communicate.

\section{Summary}

Instructors and students are both using technology to communicate, in- and outside the classroom (Clark-Gordon, Bowman, Watts, Banks, \& Knight, 2018; Fusani, 1994). MMT, translated to the student-instructor context, would predict that the stronger the tie, the more channels will be used for OCC (i.e., Haythornthwaite, 2005). OCC has been shown to lead to positive student outcomes, including motivation, affective, and 
cognitive learning (Knapp \& Martin, 2002; Goldman et al., 2016). Therefore, what is unknown is if the number of media channels (the multiplexity) of student-instructor OCC impacts student perceptions in the same way as patterns that exist in past research.

Additionally, individual differences in attitude toward online communication would also impact which modalities are used by conversational partners. To test the interplay between tie strength, multimodal OCC, and student outcomes, the following model is proposed, incorporating all hypotheses offered to this point:

Figure 1. Conceptual Model

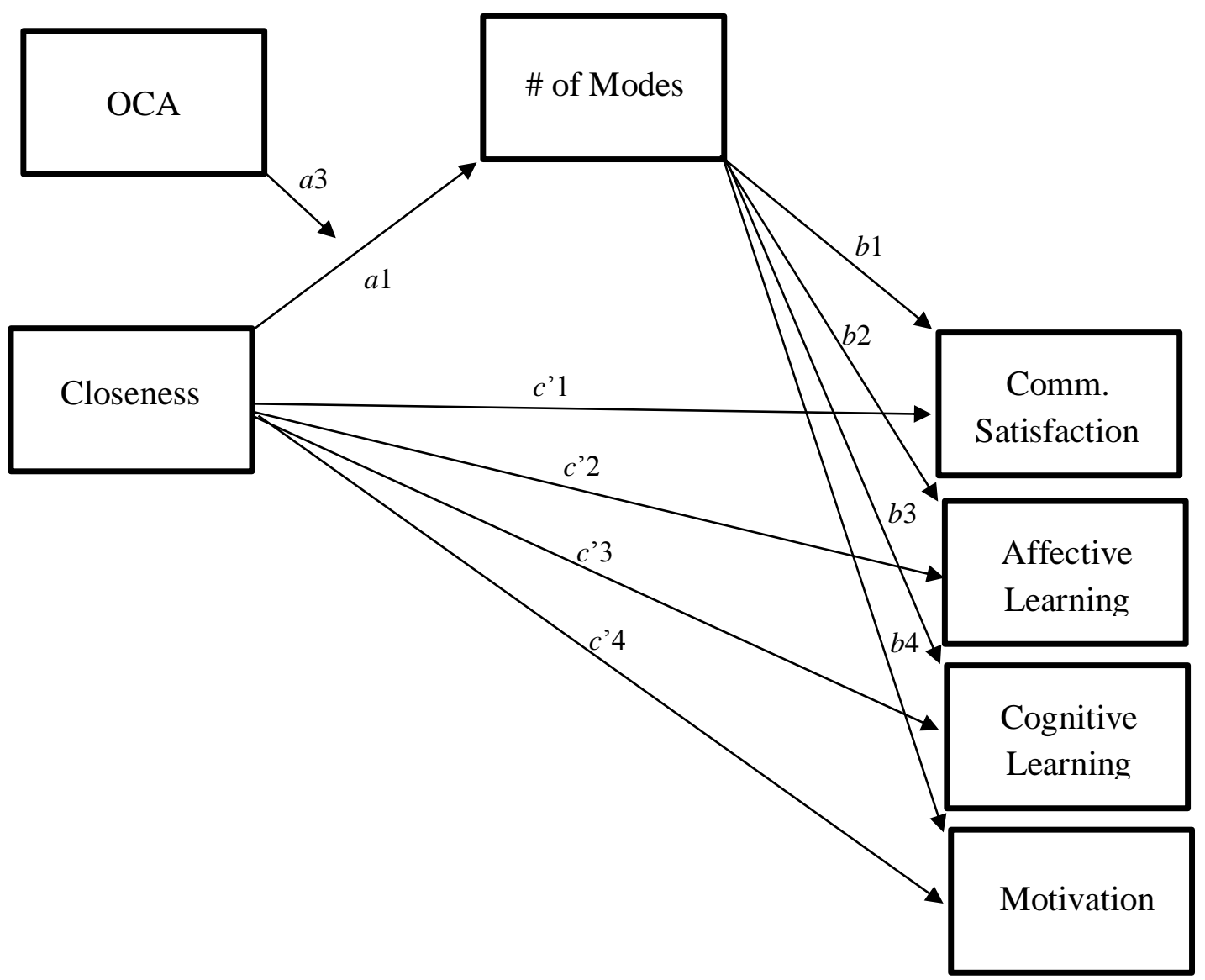


Note. Path labels above are provided for ease of interpretation: al represents the effect of closeness (tie strength) on multimodality, $b l$ through $b 4$ represent the effect of multimodality on outcome variables communication satisfaction, affective and cognitive learning, and motivation, while controlling for closeness, and $c^{\prime} 1$ through $c$ ' 4 represent the effect of closeness on outcome variables communication satisfaction, affective and cognitive learning, and motivation, while controlling for multiplexity. Path a3 represents the interaction term of closeness and online communication attitude.

\section{CHAPTER 2}

\section{Study 1}

Study 1 focused on the undergraduate student population. Undergraduate students may have a professor for only one semester before relational dissolution, and they could have larger class sizes, creating challenges for fostering a close connection between the instructor and the student. Despite these challenges, evidence suggests that undergraduate students can form interpersonal relationships with their instructors that lead to out-ofclass communication (i.e., Dobransky \& Frymier, 2004), so study one seeks to extend this claim to multimodal OCC. Theories of student psychosocial development suggest that students must go through a stage of developing mature interpersonal relationships (i.e., Chickering \& Reisser, 1993). This interpersonal aspect of student psychosocial development has been shown to be true for undergraduate student relationships with their professors (Jones \& Abes, 2013). Because interpersonal relationships can occur at all stages of higher education, undergraduate students were sampled for Study 1.

\section{Participants}

Participants $(N=269)$ were undergraduate students recruited from a large MidAtlantic university and via email recruitment messages. The sample consisted of 64 firstyear students (23.8\%), 71 sophomores (26.4\%), 59 juniors $(21.9 \%)$, and 75 seniors $(27.9 \%)$. Students were enrolled in wide variety of degree programs, including 
accounting, biology, criminology, engineering, sociology, public health, wildlife resource management, music education and performance, exercise physiology, fashion merchandising, and many others. The average participant was 20.47 years old $(\mathrm{SD}=$ $2.659)$ and the majority of the sample was White/Caucasian ( $n=226 ; 84.01 \%)$, with additional representation from African American $(n=8 ; 2.97 \%)$, Middle Eastern $(n=6$; $2.23 \%)$, and Latinx ( $n=10 ; 3.72 \%)$ communities. Nineteen participants $(7.07 \%)$ reported biracial, multiracial, or did not report on their identities. To obtain this sample, an email was sent to all active undergraduate students at the host university. Undergraduate participants were entered into a drawing for a chance to win one of five $\$ 50$ Amazon.com gift cards as incentive for their participation.

\section{Procedures}

After obtaining IRB approval, an online advertisement for the research study was posted, as per the aforementioned recruitment strategies (see Appendix A for study advertisement). Undergraduate student participants then visited the URL listed in the advertisement to participate in the study. The URL in the study advertisement linked to an online survey hosted by Qualtrics. Upon opening the link, participants viewed a cover letter (see Appendix B for cover letter). If they chose to continue to the next page, they agreed to participate in the research survey. Next, participants were randomly assigned to one of two conditions: they were either be asked to (a) report on the instructor that they are the closest to, or they reported on (b) one instructor they had for a course in the previous semester. Students will be asked to report on a close or a recent professor to combat issues associated restriction of range in tie strength; reporting only on close professors may create ceiling effects in tie strength, while reporting only on a recent 
professor may create a floor effect in tie strength.

Next, the participants were asked a series of priming questions to elicit reflection about their relationship with that professor/instructor. These questions included how many courses they have taken with their instructor, what the names of the courses were, and a favorite topic covered in a course taught by the instructor. Then, participants responded to the measures for core variables (outlined below), and demographic questions were asked at the end of the survey. Before the survey had ended, participants were given the option to enter into a drawing for one of five $\$ 50$ Amazon.com gift cards, and were redirected to a second survey to enter their preferred contact information should they choose to enter into the drawing. The researcher, at the conclusion of data collection, used a random number generator to select winning participants and contact them with their prize. The second survey was used so that no identifying information from participants from the drawing can be connected back to their responses provided in the research survey.

\section{Measures}

Tie Strength. Tie strength was measured using four items as originally outlined by Granovetter (1973) and refined by Marsden and Campbell (1984; 2012) and Haythornthwaite (2005).

Time. Time was measured through three dimensions: duration, frequency, and closeness (i.e., Granovetter, 1973; Marsden \& Campbell, 1984). Duration is the amount of time spent in the relationship (i.e, how long have you known [target's name] personally?). The response option for this study was the number of months, as the average semester is approximately four months in length. Undergraduate students 
reported that they had known their instructors for an average of 9.26 months $(S D=9.09)$. Frequency was measured as how often a tied pair communicates, (i.e., how often do you communicate with [target's name]?). Response options for the frequency question were the number of times communication occurs in an average week. Undergraduate students reported that they spoke with their professors an average of 2.12 times per week $(S D=$ 1.69). Closeness, which measures the intensity of the relationship, has in the past been measured by a trichotomy: (1) an acquaintance, (2) a good friend, or (3) a very close friend (i.e., Marsden and Campbell, 1984). Granovetter (1973) suggested a similar trichotomy of strong, weak, and absent ties. Instead of using a trichotomous variable (strong, weak, and absent), continuous variables were used to measure closeness in the present study (discussed below as measures of closeness).

Depth. As per Marsden and Campbell's (1984; 2012) work, depth was measured by one item that accounts for the number of topics that are discussed between the instructor and the student. This is drawn from Granovetter's (1973) conceptualization of mutual confiding as intimacy. Past work has used the topic of family, friends, politics, local events, work, and leisure (i.e., Marsden \& Campbell, 1984). For this study, Jaasma and Koper's (2001) functional typology of OCC topics was used, as it is based on past qualitative research on the student-instructor relationship. The functional typology includes the following topics of OCC: course-related, self-disclosure, small talk, advice, intellectual ideas, and favor requests. An additional text field was provided for participants to fill in other topics that may be covered in their communication with their instructions. When asked what topics they discussed with their instructors outside of the classroom, according to Jaasma and Koper's (2001) typology, 263 students (97\%) 
reported they discussed course-related topics, 155 students (57.2\%) used small talk, 142 students (52.4\%) asked for advice, 131 students said they discussed intellectual ideas (48.3\%), 35 students $(12.9 \%)$ reported that they would ask for a favor, 28 students $(10.3 \%)$ engaged in self-disclosure with their professor, and 15 students $(5.5 \%)$ provided other topics that came up during their OCC with their professor. Other topics covered during OCC included career and internship ideas, research opportunities, family, religion, or other personal problems.

Closeness. Two measures of closeness were employed for the present study. Vangelisti and Caughlin's (1997) measure of interpersonal closeness was used to capture the dimension of closeness using seven items that had been edited to fit the context of the study, such as "How close are you to your professor?" and "How much do you like your professor?" Response options were set as a 7-point Likert format, ranging from 1 (not at all) to 5 (a great deal). The closeness scale was found to be internally consistent in the present study $(\alpha=.91, M=3.23, S D=.95)$. Dobransky and Frymier's (2004) teacherstudent intimacy measure was used as an alternative way for students to rate their perception of closeness with their instructor. Specifically, participants were asked to rate the level of closeness of the student-instructor relationship on a seven-step, semantic differential scale using adjective pairs such as close/distant and intimate/not intimate. The intimacy scale was found to be internally consistent in the current study ( $\alpha=.87, M=$ $3.34, S D=1.31)$

Multiplexity. For the present study, the number of channels/modes used to communicate was used to determine the multiplexity of communication in the studentinstructor relationship. Participants were presented with a list of modalities, and were 
asked to check all those that apply. The list of modalities presented to participants featured modalities that had been used in extant research, as well as modes unique to the student-instructor relationship, developed for use in the present study.

To develop the list of modalities, a pilot test was employed. Reporting on the class they had most recently attended, student participants $(N=293)$ responded to an open-ended questionnaire asking them to generate an exhaustive list of all of the ways they communicate their professor. These modes could be initiated by either the student or the professor. Frequency counts were generated from the list of modes provided by students, and the results from this pilot test are listed in Table 1. Of the 293 participants, the average student used $2.86(S D=.94)$ modalities for communication with their instructor.

Table 1. Frequency of modality occurrence in student-instructor communication

\begin{tabular}{lc}
\hline \multicolumn{1}{c}{ Mode } & Frequency \\
\hline Face-to-Face & $90.8 \%(n=266)$ \\
Email & $95.2 \%(n=279)$ \\
Learning Management System & $69.9 \%(n=205)$ \\
$\quad$ (i.e.,. eCampus, Blackboard, Sole, etc.) & \\
Physical Papers/Assignments & $1.0 \%(n=3)$ \\
Class Discussion Board/Blog & $3.8 \%(n=11)$ \\
Text Messaging & $1.7 \%(n=5)$ \\
Phone Calls & $4.1 \%(n=12)$ \\
Office Hours & $12.3 \%(n=36)$ \\
Google Classroom & $1.0 \%(n=3)$ \\
Facebook & $1.7 \%(n=5)$ \\
LinkedIn & $0.3 \%(n=1)$ \\
Twitter & $0.7 \%(n=2)$ \\
Remind App & $0.7 \%(n=2)$ \\
Snapchat & $0.3 \%(n=1)$ \\
Video Call & $0.3 \%(n=1)$ \\
\hline
\end{tabular}

This pilot data was compared with measures of multimodality used in past research (see Table 2) to formulate a final measurement (see Appendix $\mathrm{C}$ for the final list of channels, 
and for a complete list of measures).

Table 2. Modalities used as response options in previous MMT and OCC research

\begin{tabular}{|c|c|c|c|}
\hline $\begin{array}{l}\text { Haythornthwaite } \\
\text { (2005) }\end{array}$ & $\begin{array}{l}\text { Ledbetter }(\mathbf{2 0 0 9 b}) \\
\text { drawn from Scott \& } \\
\text { Timmerman }(2005)\end{array}$ & $\begin{array}{c}\text { Caughlin \& Sharabi } \\
\text { (2013) } \\
\text { drawn from focus } \\
\text { groups }\end{array}$ & $\begin{array}{l}\text { Vareburg et al. } \\
\text { (2018) } \\
\text { drawn from open- } \\
\text { ended survey } \\
\text { questions }\end{array}$ \\
\hline $\begin{array}{l}\text { Scheduled FtF } \\
\text { Meetings }\end{array}$ & Face-to-face & $\begin{array}{l}\text { Private Internet } \\
\text { messaging }\end{array}$ & $\begin{array}{l}\text { Messages sent } \\
\text { through LMS } \\
\text { (BlackBoard, } \\
\text { eCampus, etc.) }\end{array}$ \\
\hline $\begin{array}{l}\text { Unscheduled FtF } \\
\text { Meetings }\end{array}$ & Telephone & $\begin{array}{l}\text { Public Internet } \\
\text { messaging }\end{array}$ & $\begin{array}{l}\text { Doc Sharing Systesm } \\
\text { (e.g., Google Docs) }\end{array}$ \\
\hline Email & $\begin{array}{l}\text { Social Networking } \\
\text { Websites }\end{array}$ & Text messaging & $\begin{array}{l}\text { Discussion Boards } \\
\text { (e.g., Slack) }\end{array}$ \\
\hline IM/Chat & $\mathrm{B} \log \mathrm{s}$ & Internet chat & Text messaging \\
\hline \multirow[t]{2}{*}{ Phone Calls } & $\begin{array}{l}\text { Other forms of online } \\
\text { communication } \\
\text { (discussion boards, } \\
\text { online games) }\end{array}$ & Video chat & Video calling \\
\hline & Postal mail & Phone calls & Social Media \\
\hline
\end{tabular}

This final list of modalities was presented to participants using the Scott and Timmerman's (2005) approach, where participants ranked the frequency of occurrence of communication of each modality, ranging from 1 for never to 6 for very frequently. After students selected the frequency of modalities from this list, their response options carried forward to two additional questions. One question asked participants which communication modalities were required by their instructor (of the options they had already chosen), and the second question asked participants who initiated communication via each channel they had already selected: the student, the instructor, or both. Responses 
to these descriptive questions are listed in the Results section in Table 3.

Satisfaction. The extent to which students' were satisfied with their instructor's multimodal communication habits was measured using Goodboy, Martin, and Bolkan's (2009) eight-item scale. A 7-point Likert scale ranging from 1 (strongly disagree) to 7 (strongly agree) was used to evaluate students' level of agreement with items such as "talking with my teacher leaves me feeling like I accomplished something," and "my teacher fulfills my expectations when I talk to him/her." This measure was found to be internally consistent in the current study $(\alpha=.94, M=5.63, S D=1.25)$.

Cognitive learning. Perceived cognitive learning was measured using Frymier and Houser's (1999) revised learning indicators scale. The revised learning indicators scale consists of seven items that reflect learning activities that students may engage in when involved in the cognitive learning process, such as "I think about the course content outside of class" and "I see connections between the course content and my career goals." Participants were asked to indicate how frequently they perform each of the behaviors using a 5-point Likert-type scale ranging from 1 (never) to 5 (very often). The measure was found to be internally consistent in the current study $(\alpha=.87, M=3.76, S D=.91)$.

Affective learning. Affective learning was measured using subscales from the Instructional Affect Assessment Instrument (IAAI; McCroskey, 1994). The IAAI is a 24item scale that measures student affect across six subscales. In this study, two of the six subscales will be used to measure student affective learning. Affect toward the instructor was measured by a four-item subscale that asks students to report on their attitude toward the course instructor (good/bad, worthless/valuable, fair/unfair, negative/positive). Affect toward the course content was also measured with a four-item subscale that asks students 
to report on their attitude toward the course content (good/ bad, worthless/valuable, fair/unfair, negative/positive). All items were featured as bipolar adjectives, set with seven steps between each adjective. Both affect towards the class $(\alpha=.86, M=6.11, S D$ $=1.13)$ and affect towards the instructor $(\alpha=.91, M=6.17, S D=1.33)$ were internally consistent in the present study.

Motivation. Student motivation was measured using Christophel's (1990) 12item measure of state motivation. The measure utilizes bipolar statements set on a 7-point semantic differential response options. Example adjective pairs include "motivated/unmotivated," "interested/uninterested," and "involved/uninvolved." The motivation measure was internally consistent in the present sample $(\alpha=.92, M=5.43$, $S D=1.17)$

Online communication attitude. Online communication attitude (OCA) was measured using one dimension of Ledbetter's (2009a) OCA: Enjoyment/Ease. The Enjoyment OCA is a six-item measure, consisting of items such as "Online communication is convenient, and "I enjoy communicating online." Participants responded on a seven-point Likert-type scale with response options ranging from 1 (strongly disagree) to 7 (strongly agree). The present study found this measure to be internally consistent $(\alpha=.89, M=5.62, S D=1.52)$.

\section{Summary}

Undergraduate students took online surveys, asking them to report on either (a) their closest instructor or (b) an instructor they took a course with in the previous semester. Participants were recruited through a network sample, using offices at the host institution to begin sampling procedures. Once recruited, participants took the survey 
online, featuring the core variables of the study. They then were entered into a random drawing for Amazon.com gift cards.

\section{CHAPTER 3}

Study 1 Results

\section{Descriptive Findings}

Of the undergraduate students in the sample of the present study, $119(44.1 \%)$ reported on a close professor and $151(55.9 \%)$ reported on an instructor they had in the previous academic semester. The undergraduate students used an average of $4.32(\mathrm{SD}=$ 2.43) modes to communicate with their professors. Students were asked to report on how often they use certain modalities, if it was required for their class, and who initiated the communication via each mode (the student or the instructor, see Table 3).

Table 3. Study 1 Modality Usage Descriptive Statistics

\begin{tabular}{|c|c|c|c|c|c|c|c|}
\hline \multirow[t]{2}{*}{ Mode } & \multirow[b]{2}{*}{$\begin{array}{l}\text { Total \# of } \\
\text { Students }\end{array}$} & \multicolumn{2}{|c|}{$\begin{array}{c}\text { Frequency } \\
\text { of Use }\end{array}$} & \multicolumn{2}{|c|}{$\begin{array}{c}\text { Class } \\
\text { Requirement }\end{array}$} & \multicolumn{2}{|c|}{$\begin{array}{c}\text { Communication } \\
\text { Initiation }\end{array}$} \\
\hline & & $M$ & $S D$ & $\begin{array}{c}\text { \# of } \\
\text { Students }\end{array}$ & $\%$ & $M$ & $S D$ \\
\hline Face-to-Face & $257(95.5 \%)$ & 4.44 & 1.31 & 196 & $72.3 \%$ & 4.67 & 2.67 \\
\hline Email & $261(96.6 \%)$ & 4.06 & 1.19 & 120 & $44.3 \%$ & 4.39 & 3.06 \\
\hline LMS & $180(66.6 \%)$ & 2.61 & 1.51 & 108 & $39.9 \%$ & 7.22 & 3.11 \\
\hline $\begin{array}{l}\text { Discussion } \\
\text { Boards }\end{array}$ & $116(42.9 \%)$ & 2.09 & 1.51 & 49 & $18.1 \%$ & 5.94 & 3.34 \\
\hline $\begin{array}{l}\text { Document } \\
\text { Sharing } \\
\text { Systems }\end{array}$ & $99(36.6 \%)$ & 1.91 & 1.43 & 36 & $13.3 \%$ & 5.31 & 3.24 \\
\hline $\begin{array}{l}\text { Google } \\
\text { Classroom }\end{array}$ & $43(15.9 \%)$ & 1.39 & 1.04 & 13 & $4.8 \%$ & 5.51 & 3.17 \\
\hline Phone Calls & $33(12.2 \%)$ & 1.27 & 0.81 & 1 & $0.4 \%$ & 4.94 & 2.63 \\
\hline Video Chat & $16(5.9 \%)$ & 1.15 & 0.67 & 0 & $0.0 \%$ & 4.98 & 2.30 \\
\hline $\begin{array}{l}\text { Text } \\
\text { Messaging }\end{array}$ & $34(12.6 \%)$ & 1.33 & 0.97 & 2 & $0.7 \%$ & 4.79 & 2.44 \\
\hline $\begin{array}{l}\text { Instant } \\
\text { Messaging }\end{array}$ & $16(5.9 \%)$ & 1.16 & 0.72 & 1 & $0.4 \%$ & 5.32 & 2.29 \\
\hline Handwritten & $68(25.2 \%)$ & 1.70 & 1.35 & 16 & $5.9 \%$ & 6.34 & 2.95 \\
\hline Social Media & $25(9.3 \%)$ & 1.24 & 0.83 & 0 & $0.0 \%$ & 5.56 & 2.56 \\
\hline
\end{tabular}




\begin{tabular}{llllllll} 
Apps & $10(3.7 \%)$ & 1.09 & 0.49 & 0 & $0.0 \%$ & 5.39 & 2.31 \\
Online & $6(1.1 \%)$ & 1.05 & 0.39 & 0 & $0.0 \%$ & 4.98 & 2.55 \\
Gaming & & & & & & & \\
\hline
\end{tabular}

Note. Frequency was measured using a 6-point Likert-type scale. Who initiated the communication was measured using a 10-point scale, with a score of 10 indicating the instructor initiated more communication via that channel, a score of 1 indicating the student initiated more communication via that channel, and a score of 5 indicating an equal amount of communication initiation.

\section{Measurement Model}

To test the proposed model (H1, H2, and H3, featured in Figure 1), a structural equation modeling (SEM) approach was used, following with the suggestions of Kline (2016) for evaluating measurement and path models. The measurement model was analyzed using Mplus SEM software. In the measurement model, all latent variables in the study were specified to covary, as per Kline's (2016) recommendations. Using maximum-likelihood robust estimation (MLR), the model fit criteria were: a nonsignificant chi-square; a comparative fit index $(\mathrm{CFI}) \geq .95$; a root mean square error of approximation (RMSEA) $\leq .08$ accompanied by a $90 \%$ confidence interval with an upper bound of .10 or less, and a standardized root-mean-residual $(\mathrm{SRMR}) \leq .08(\mathrm{Hu} \&$ Bentler, 1999; Kline, 2016).The results of the CFA yielded the following global modal fit: Satorra-Bentler $\chi^{2}(1297)=2802.21, p<.001$, MLR Scaling Correction Factor $=$ 1.153, RMSEA $=.066$ [90\% CI: .063, .069], CFI $=.835, \mathrm{SRMR}=.069$.

Due to some global misfit in the measurement model, local fit was examined through an inspection of the standardized residual covariance matrix, using the cutoff of the critical value of $+/-2.58$ needed for a .99 confidence level (Bandalos, 2018; Privitera, 2015). Standardized residuals, ranged from 0.01 to 59.31. Standardized residuals exceeding the $+/-2.58$ critical threshold for $z$-scores were further explored through 
modification indices. The modification indices suggested that the large residuals in the present model resulted from the error terms of similar items not being specified to covary in the measurement model. For example, items two and three on the Revised Learning Indicator Scale (Frymier \& Houser, 1999) are highly correlated $(r=.54)$ and had a large residual $(z=59.31)$, and modification indices suggested by correlating these two items, the chi-square value for the global fit of the model would be reduced by 37.41 . However, no model specifications were made to correlate error terms on items within any of the scales used for the present study. Gerbing and Andersen (1984) argue that the uncritical use of correlated measurement errors, without theoretical justification, leads to merely more acceptable fit, while obfuscating a more meaningful theoretical structure. Therefore, despite the significant chi-square, the model was retained, as in line with the recommendations of Asparouhov and Muthén (2018) who suggest that measurement models can be retained with a significant chisquare test when the SRMR is $\leq .08$ and the sample size is larger than 200 (see Table 4 for factor loadings). These recommendations are made because of the SRMR's sensitivity to sample size, and when a chi-square rejects a model but the SRMR retains it, it is still an approximately well-fitting model (not an exact fitting model, as would be the case for a model with a non-significant chi-square and an SRMR $<.08$ ).

Table 4. Study 1 Measurement Model

\begin{tabular}{cc}
\hline Variable Item & $\begin{array}{c}\text { Factor } \\
\text { Loading }\end{array}$ \\
\hline Intimacy (Dobransky \& Frymier, 2004) & .81 \\
Warm/Cold & .61 \\
Intimate/Not Intimate & .76 \\
Emotionally close/Emotionally distant & .77 \\
Familiar/Unfamiliar & .83 \\
Caring/Not Caring &
\end{tabular}


Closeness (Vangelisti \& Caughlin, 1999)

How close are you to your instructor of [class name]? $\quad .79$

How much do you like your instructor of [class name]? $\quad .80$

How often do you talk about personal things with your $\quad .67$

instructor of [class name]?

How important is your instructor of [class name]'s $\quad .77$

opinion to you?

How satisfied are you with your relationship with your $\quad .74$

instructor of [class name]?

How much do you enjoy spending time with your $\quad .88$

instructor of [class name]?

How important is your relationship with your instructor $\quad .75$

of [class name]?

Communication Satisfaction (Goodboy et al., 2009)

My communication with my instructor feels satisfying. $\quad .82$

I dislike talking with my instructor.* ${ }^{*} \quad .65$

I am not satisfied after talking to my instructor.* $\quad .56$

Talking with my instructor leaves me feeling like I $\quad .87$

accomplished something.

My instructor fulfills my expectations when I talk to $\quad .94$

them.

My conversations with my instructor are worthwhile. $\quad .94$

When I talk to my instructor, the conversations are $\quad .90$

rewarding.

My instructor makes an effort to satisfy the concerns I $\quad .88$

have.

Affect toward Class (McCroskey, 1994)

$\mathrm{Bad} / \mathrm{Good}^{*}$

Valuable/Worthless $\quad .64$

Unfair/Fair* $\quad .86$

Positive/Negative $\quad .82$

Affect toward Instructor (McCroskey, 1994)

$\mathrm{Bad} /$ Good* $^{*}$

.91

Valuable/Worthless $\quad .78$

Unfair/Fair* $\quad .88$

Positive/Negative $\quad .83$

Motivation (Christophel, 1990)

Motivated/Unmotivated $\quad .81$

Interested/Uninterested $\quad .85$

Involved/Uninvolved $\quad .75$

Not Stimulated/Stimulated* $\quad .72$

Don't want to study/Want to study* $\quad .58$

Inspired/Uninspired $\quad .81$

Unchallenged/Challenged* ${ }^{*} \quad .50$

Uninvigorated/Invigorated* $\quad .70$

Unenthused/Enthused* $\quad .84$ 
Excited/Not Excited $\quad .72$

Aroused/Not aroused $\quad .44$

Not fascinated/Fascinated ${ }^{*} \quad .77$

Cognitive Learning (Frymier \& Houser, 1999)

I like to talk about what I'm doing in class with friends $\quad .56$ and family.

I explain course content to other students.

I think about the course content outside the class. $\quad .70$

I see connections between the course content and my $\quad .80$ career goals.

I review the course content.

I compare the information from this class with other $\quad .81$ things I have learned.

I feel I have learned a lot in this class. $\quad .78$

Online Communication Attitude (Ledbetter, 2009a)

Online communication is convenient. $\quad .80$

I enjoy communicating online.

I like that it is easy to get ahold of people through online $\quad .85$

communication.

When life gets busy, online communication is a great $\quad .79$

way to communicate efficiently.

Online communication is a stress-free way to get in $\quad .65$

touch with someone.

Online communication is fun.

.68

Note. All factor loadings were significant at the $p<.001$ level. Reverse-coded items are marked with an asterisk.

\section{Hypothesized Model Results}

After retention of the measurement model, a path model approach was conducted using the composite variables outlined above. Using Mplus software, maximum likelihood estimation was used to test the hypothesized model, as were the aforementioned global and local fit criteria. However, the measure of intimacy was excluded from the path model, because of its high correlation with closeness $(r=.77, p<$ .01 ), but also because of MMT's focus on the construct of closeness (not intimacy, a similar but differentiated construct; see Table 5 for correlation matrix of all variables used in Study 1).

Table 5. Study 1 Pearson Correlations 


\begin{tabular}{|c|c|c|c|c|c|c|c|}
\hline Variable & 2. & 3. & 4. & 5. & 6. & 7. & 8. \\
\hline 1. Closeness & $.776^{* *}$ & $.460 * *$ & $.560 * *$ & $.596^{* * *}$ & $.646 * *$ & $.224 * *$ & $.268 * *$ \\
\hline 2. Comm. Satisfaction & -- & $.467 * *$ & $.609 * *$ & $.718^{* *}$ & $.667 * *$ & $.282 * *$ & $.152 *$ \\
\hline 3. Cognitive Learning & & -- & $.496 * *$ & $.317 * *$ & $.549 * *$ & $.271 * *$ & .119 \\
\hline 4. Affect toward Class & & & -- & $.760 * *$ & $.684 * *$ & $.186^{* *} *$ & $.128 *$ \\
\hline 5. Affect toward & & & & -- & $.594 * *$ & $.187 * *$ & $.138^{*}$ \\
\hline \multicolumn{8}{|l|}{ Instructor } \\
\hline 6. Motivation & & & & & -- & $.239 * *$ & $.163 * *$ \\
\hline 7. OCA & & & & & & -- & .085 \\
\hline 8. \# of Modes & & & & & & & -- \\
\hline
\end{tabular}

Note. ** Correlation is significant at the $p<.01$ level. * Correlation is significant at the $p<.05$ level.

Additionally, the independent $(X)$ and moderator $(W)$ variable were meancentered for ease of interpretability of the $a$ path (H1; see Figure 1 for conceptual model). Centering variables involved in an interaction term render paths interpretable and their hypothesis tests meaningful (Hayes, 2018). Hayes (2018) suggests centering $X$ and $W$ when there is no meaningful zero-point in the measurement of $W$ (such as when using Likert response options). After mean-centering $X$ and $W$, the $a$ path then estimates the difference in $M$ between two cases that differ by one unit on $W$ among cases that are average on $X$. Therefore, both closeness $(X)$ and OCA $(W)$ were mean-centered for the present study. Using maximum likelihood estimation with 10,000 percentile bootstraps, global fit revealed that the path model fit well: $\chi^{2}(10)=24.73, p=.006, \mathrm{RMSEA}=.08$ [90\% CI: .04, .11], CFI = .99, SRMR = .04 (for path estimates see Figure 2). 
Figure 2. Study 1 Hypothesized Model

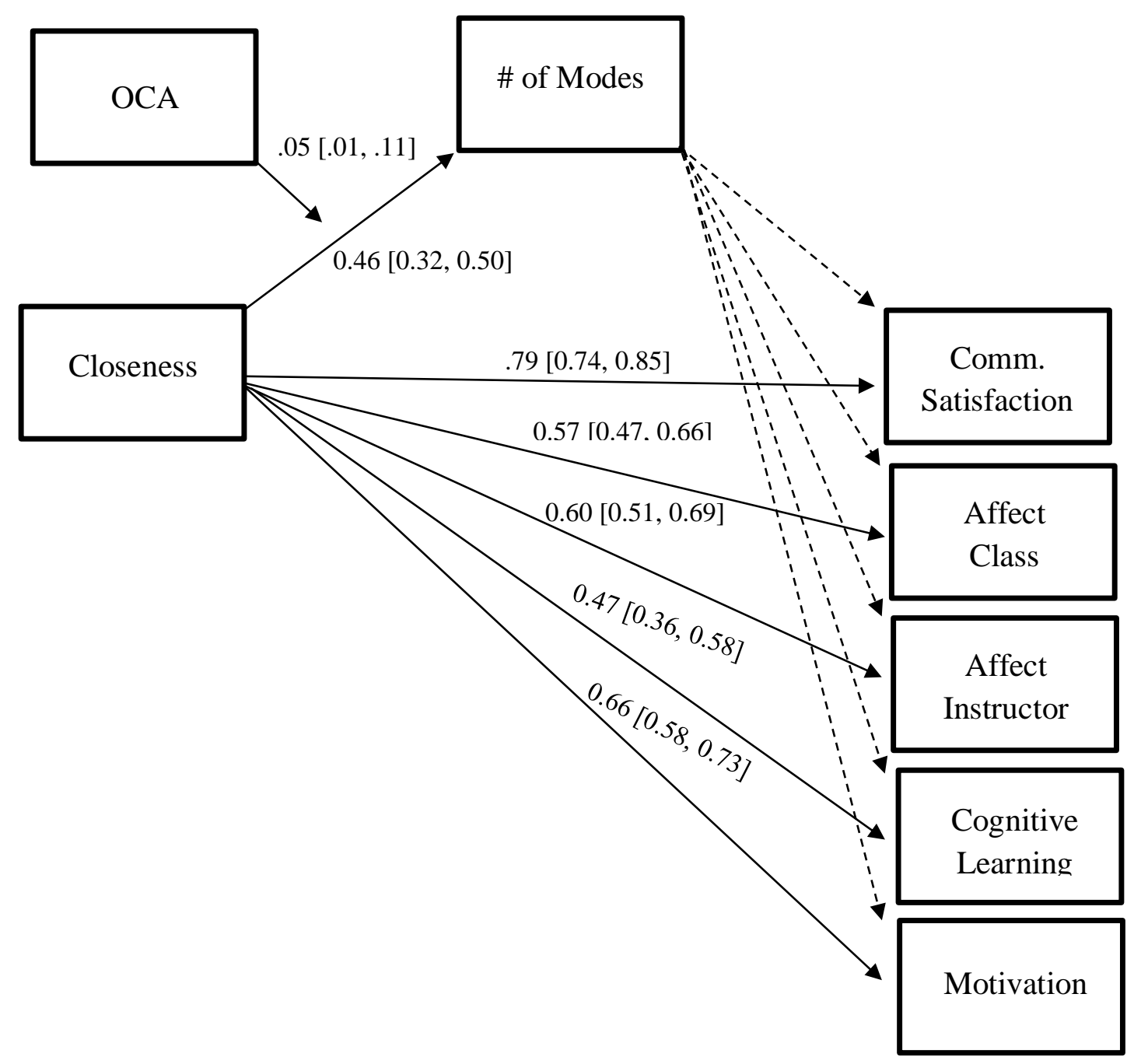

Note. All estimates are standardized, and confidence intervals were generated using 10,000 percentile bootstraps. Confidence intervals excluding zero are shown, while those including zero are featured as dashed paths.

After acceptable global was achieved in the path model, path coefficients were interpreted to answer $\mathrm{H} 1, \mathrm{H} 2$, and $\mathrm{H} 3$. For analysis of $\mathrm{H} 3$, which regards a moderating variable (online communication attitude), effects were examined by specifying an interaction term within the structural equation model context between the independent variable (closeness) and the moderating variable (online communication attitude). Results 
of the path analysis suggested there were positive direct effects on all five learning outcomes, as well as a positive interaction effect between closeness and online communication attitude on media multiplexity (see Figure 2). However, there was no evidence to suggest that closeness had indirect effects on any of the student outcomes (through the mediator of multimodality), as the bootstrapped confidence interval included zero in the index of moderated mediation for each outcome (see Table 6).

With respect to the core predictions of this study, $\mathrm{H} 1$ predicted that the number of modes used to communicate would increase instructor and student closeness, and $\mathrm{H} 2$ predicted that the number of modes used to communicate would positively predict student outcomes. The results from the hypothesized model do provide evidence to support H1 $\left(R^{2}=.109\right)$, but does not support H2. Instead, the data suggests multiplexity (the number of modes used to communicate) had no significant direct effects on the positive student outcomes of communication satisfaction $\left(R^{2}=.595\right)$, affect toward the instructor $\left(R^{2}=.324\right)$, affect toward the course $\left(R^{2}=.289\right)$, cognitive learning $\left(R^{2}=.195\right)$, or motivation $\left(R^{2}=.394\right)$. H3, however, was supported. As enjoyment toward communicating online increased, so did instructor-student closeness when communicating through multiple modalities.

Table 6. Study 1 Conditional Indirect Effects for Hypothesized Model

\begin{tabular}{ccccc}
\hline Index of Moderated Mediation (IMM) & & \multicolumn{3}{c}{ Bootstrapped CI } \\
\hline Conditional Indirect Effects & Effect & $S E$ & LLCI & ULCI \\
\hline Communication Satisfaction (IMM) & $\mathbf{- 0 . 0 0 8}$ & $\mathbf{0 . 0 0 6}$ & $\mathbf{- 0 . 0 1 9}$ & $\mathbf{0 . 0 0 4}$ \\
$\theta_{\mathrm{a} / \mathrm{OCA}}=4.47(-1 S D)$ & -0.004 & 0.004 & -0.012 & 0.009 \\
$\theta_{\mathrm{ab} / \mathrm{OCA}}=5.62(M)$ & -0.014 & 0.010 & -0.031 & 0.018 \\
$\theta_{\mathrm{ab} / \mathrm{OCA}}=6.77(+1 S D)$ & -0.023 & 0.016 & -0.051 & 0.027 \\
Cognitive Learning $(\mathbf{I M M )}$ & $\mathbf{0 . 0 0 0}$ & $\mathbf{0 . 0 0 7}$ & $\mathbf{- 0 . 0 1 3}$ & $\mathbf{0 . 0 1 3}$ \\
$\theta_{\mathrm{ab} / \mathrm{OCA}}=4.47(-1 S D)$ & 0.000 & 0.004 & -0.006 & 0.012 \\
$\theta_{\mathrm{ab} / \mathrm{OCA}}=5.62(M)$ & -0.001 & 0.012 & -0.019 & 0.027 \\
$\theta_{\mathrm{a} / \mathrm{OCA}}=6.77(+1 S D)$ & -0.001 & 0.019 & -0.033 & 0.042
\end{tabular}




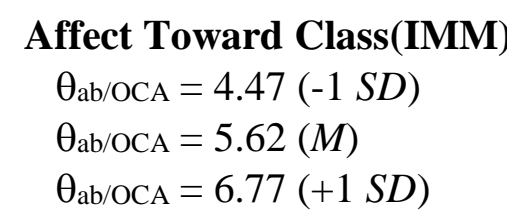

Affect Toward Instructor (IMM)

$\theta_{\mathrm{ab} / \mathrm{OCA}}=4.47(-1 S D)$

$\theta_{\mathrm{ab} / \mathrm{OCA}}=5.62(M)$

$\theta_{\mathrm{ab} / \mathrm{OCA}}=6.77(+1 S D)$

Motivation (IMM)

$\theta_{\mathrm{ab} / \mathrm{OCA}}=4.47(-1 S D)$

$\theta_{\mathrm{ab} / \mathrm{OCA}}=5.62(M)$

$\theta_{\mathrm{ab} / \mathrm{OCA}}=6.77(+1 S D)$

$\begin{array}{llll}\mathbf{- 0 . 0 0 3} & \mathbf{0 . 0 0 8} & \mathbf{- 0 . 0 1 8} & \mathbf{0 . 0 1 4} \\ -0.001 & 0.005 & -0.014 & 0.008 \\ -0.004 & 0.014 & -0.033 & 0.022 \\ -0.007 & 0.023 & -0.054 & 0.038 \\ -\mathbf{- 0 . 0 0 3} & \mathbf{0 . 0 0 8} & \mathbf{- 0 . 0 1 8} & \mathbf{0 . 0 1 4} \\ -0.002 & 0.005 & -0.014 & 0.008 \\ -0.005 & 0.015 & -0.035 & 0.023 \\ -0.008 & 0.024 & -0.056 & 0.040 \\ \mathbf{- 0 . 0 0 1} & \mathbf{0 . 0 0 6} & \mathbf{- 0 . 0 1 2} & \mathbf{0 . 0 1 1} \\ -0.001 & 0.004 & -0.010 & 0.007 \\ -0.002 & 0.010 & -0.023 & 0.019 \\ -0.003 & 0.017 & -0.036 & 0.031\end{array}$

Note. Evidence for conditional indirect effects are indicated by an index of moderated mediation (IMM) whose confidence interval excludes zero. Variables with conditional indirect effects are flagged with an asterisk (*) for ease of interpretation.

\section{Alternative Model Test}

In order to rule out alternative models, the same data was examined across an equally plausible model. Testing alternative models was particularly important for the predictions made in this manuscript. While $\mathrm{H} 1$ is a test of MMT and is based on evidence from extant research, $\mathrm{H} 2$ is based on extant research alone. When combined into one model, a mediation claim is created, insofar as the multiplexity of student-instructor communication (i.e., the number of modes used for student-instructor OCC) is the mechanism through which tie strength impacts student relational and academic outcomes (satisfaction, affective and cognitive learning, motivation). Because data collected was cross-sectional in nature, the requirement of time order needed to make causal claims was not met. A plausible alternative model, instead, specified modes used for OCC (the mediating variable in the hypothesized model) as the independent (exogenous) variable in the model, and then specified tie strength (the independent variable in the hypothesized model) instead as the mediator. While Haythornthwaite's (2005) work suggests that tie strength leads (i.e., closeness) to greater media used to communicate, subsequent work in 
interpersonal relationships (i.e., Ledbetter 2009b, Ledbetter \& Mazer, 2014) find that frequency of multimodal communication leads to relational interdependence (using interdependence as the operationalization for tie strength in interpersonal relationships). This suggests that tie strength (when operationalized as interdependence) can be predicted by the frequency of multimodal communication. Testing alternative models with different directionality specifications is also recommended by Kline (2016) for research designs without temporal precedence. The Akaike Information Criterion (AIC) and the Bayesian Information Criterion (BIC) were used to compare models. The AIC and BIC are used to select among competing nonhierarchical models. Specifically, the model with the smallest value of the AIC/BIC was chosen as the one most likely to replicate (Kline, 2016, p. 287). Therefore, the hypothesized model will be determined to be a better fit if both values of AIC and BIC are smaller, and that the BIC, specifically, is 10-12 units lower in the hypothesized model.

Therefore, an alternative model test was conducted also using a path model. For the alternative model, the independent and mediating variable were transposed, so that the number of modes used to communicate (i.e., the multiplexity of communication) would predict student-instructor closeness, which in turn would influence the student outcomes of communication satisfaction, motivation, and affective and cognitive learning. Using maximum likelihood estimation with 10,000 percentile bootstraps, global fit revealed that the path model also fit well: $\chi^{2}(10)=21.11, p=.02$, RMSEA $=.07[90 \%$ CI: .03, .10], CFI $=.99$, SRMR $=.04$ (for path estimates see Figure 3 ). Going beyond global fit indices, the AIC and BIC were used to compare the alternative models, as suggested by Klein (2016). The hypothesized model had an AIC of 4244.29, and a BIC of 
4368.51. The alternative model had an AIC of 3745.96 and a BIC of 3870.58. Raykov and Marcoulides (2011) recommend retaining a model if both values of AIC and BIC are smaller, and that the BIC, specifically, is 10-12 units lower in the hypothesized model. Therefore, because the alternative model's BIC was 497.93 units lower, it was retained for Study 1. The alternative model also suggests that there are no direct effects of multiplexity on student outcomes, but does suggest the presence of indirect effects (see Figure 3).

Figure 3. Study 1 Alternative Model

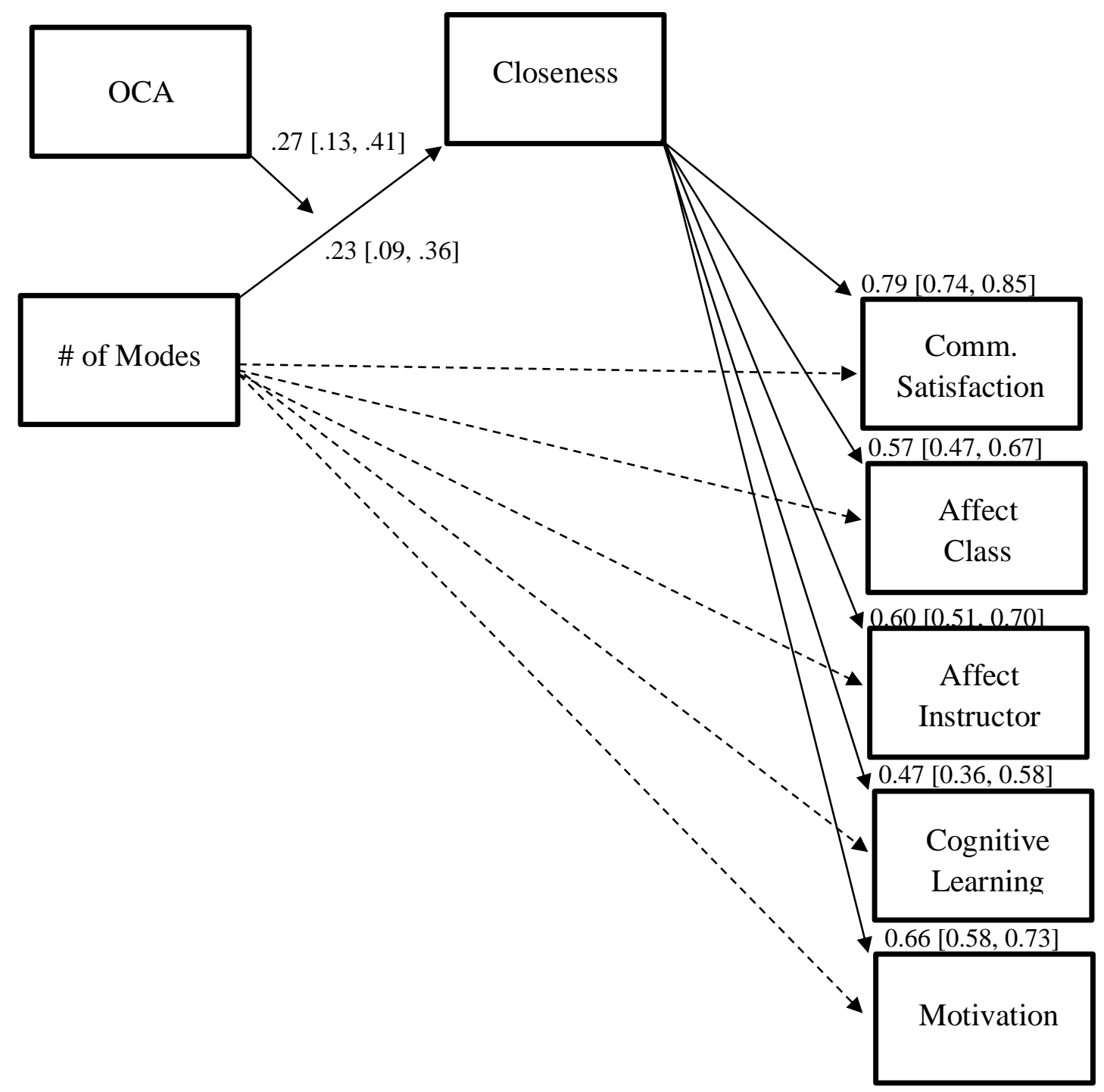


Note. All estimates are standardized, and confidence intervals were generated using 10,000 percentile bootstraps. Confidence intervals excluding zero are shown, while those including zero are featured as dashed paths.

To test for the presence of moderated mediation in the alternative model, the index of moderated mediation was generated for all five outcomes in the present study. All confidence intervals excluded zero, suggesting the presence of conditional indirect effects (see Table 7). The results convey that multimodality has an indirect effect on communication satisfaction $\left(R^{2}=.604\right)$, cognitive learning $\left(R^{2}=.204\right)$, affect toward their instructor $\left(R^{2}=.356\right)$, affect toward their class $\left(R^{2}=.311\right)$, and motivation $\left(R^{2}=\right.$ $.418)$ through students' perceptions of closeness with their instructor $\left(R^{2}=.184\right)$.

However, this effect intensifies as one's enjoyment for online communication also increases.

Table 7. Study 1 Conditional Indirect Effects for Alternative Model

\begin{tabular}{ccccc}
\hline Index of Moderated Mediation (IMM) & & \multicolumn{3}{c}{ Bootstrapped CI } \\
\hline Conditional Indirect Effects & Effect & $S E$ & LLCI & ULCI \\
\hline Communication Satisfaction (IMM)* & $\mathbf{0 . 1 5 9}$ & $\mathbf{0 . 0 2 0}$ & $\mathbf{0 . 1 3 0}$ & $\mathbf{0 . 2 0 7}$ \\
$\theta_{\mathrm{ab} / \mathrm{OCA}}=4.47(-1 S D)$ & 0.211 & 0.036 & 0.146 & 0.289 \\
$\theta_{\mathrm{a} / \mathrm{OCA}}=5.62(M)$ & 0.393 & 0.050 & 0.312 & 0.508 \\
$\theta_{\mathrm{a} / \mathrm{OCA}}=6.77(+1 S D)$ & 0.576 & 0.068 & 0.468 & 0.735 \\
Cognitive Learning $(\mathbf{I M M})^{*}$ & $\mathbf{0 . 0 6 8}$ & $\mathbf{0 . 0 1 1}$ & $\mathbf{0 . 0 5 1}$ & $\mathbf{0 . 0 9 2}$ \\
$\theta_{\mathrm{ab} / \mathrm{OCA}}=4.47(-1 S D)$ & 0.090 & 0.020 & 0.055 & 0.134 \\
$\theta_{\mathrm{ab} / \mathrm{OCA}}=5.62(M)$ & 0.169 & 0.030 & 0.117 & 0.234 \\
$\theta_{\mathrm{ab} / \mathrm{OCA}}=6.77(+1 S D)$ & 0.247 & 0.041 & 0.177 & 0.337 \\
Affect Toward Class $(\mathbf{I M M})^{*}$ & $\mathbf{0 . 1 0 2}$ & $\mathbf{0 . 0 1 8}$ & $\mathbf{0 . 0 7 5}$ & $\mathbf{0 . 1 4 5}$ \\
$\theta_{\mathrm{a} / \mathrm{OCA}}=4.47(-1 S D)$ & 0.136 & 0.026 & 0.091 & 0.194 \\
$\theta_{\mathrm{a} / \mathrm{OCA}}=5.62(M)$ & 0.254 & 0.042 & 0.186 & 0.349 \\
$\theta_{\mathrm{a} / \mathrm{OCA}}=6.77(+1 S D)$ & 0.371 & 0.061 & 0.274 & 0.513 \\
Affect Toward Instructor $(\mathbf{I M M})^{*}$ & $\mathbf{0 . 1 2 7}$ & $\mathbf{0 . 0 2 1}$ & $\mathbf{0 . 0 9 4}$ & $\mathbf{0 . 1 7 7}$ \\
$\theta_{\mathrm{ab} / \mathrm{OCA}}=4.47(-1 S D)$ & 0.168 & 0.031 & 0.144 & 0.236 \\
$\theta_{\mathrm{ab} / \mathrm{OCA}}=5.62(M)$ & 0.314 & 0.049 & 0.235 & 0.425 \\
$\theta_{\mathrm{ab} / \mathrm{OCA}}=6.77(+1 S D)$ & 0.461 & 0.071 & 0.345 & 0.677 \\
Motivation $(\mathbf{I M M}) *$ & $\mathbf{0 . 1 2 2}$ & $\mathbf{0 . 0 1 8}$ & $\mathbf{0 . 0 9 4}$ & $\mathbf{0 . 1 6 5}$ \\
$\theta_{\mathrm{ab} / \mathrm{OCA}}=4.47(-1 S D)$ & 0.161 & 0.028 & 0.113 & 0.222 \\
$\theta_{\mathrm{a} / \mathrm{OCA}}=5.62(M)$ & 0.301 & 0.042 & 0.233 & 0.398
\end{tabular}




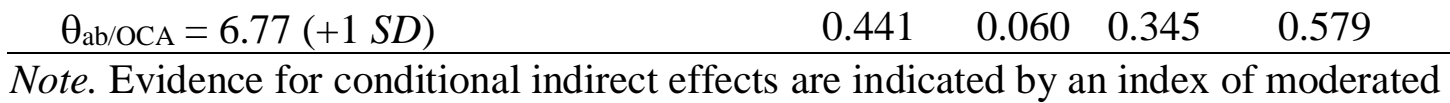
mediation (IMM) whose confidence interval excludes zero. Variables with conditional indirect effects are flagged with an asterisk $(*)$ for ease of interpretation.

\section{Summary}

The results of Study 1 on undergraduate students did not support the hypothesized model (wherein closeness predicted the positive classroom outcomes of communication satisfaction, cognitive and affective learning, and motivation). Instead, Study 1 suggested that it was the multiplexity of communication that predicted closeness, which in turn predicted the positive classroom outcomes. These effects were contingent upon enjoyment of online communication, which strengthened the effects as enjoyment for OCA increased.

\section{CHAPTER 4}

\section{Study 2 Method}

Study two replicated study one, extending the same predictions to the graduate student population. Graduate students may have potential for greater tie strength (the independent variable at the core of this study) with their professors than undergraduate students, likely due to relationship length and intimacy. Because graduate students were sampled from a large, Mid-Atlantic, R1 university, there is potential that graduate students could have professors for multiple classes across multiple semesters, allowing greater time for relational development. Graduate student class sizes may also be smaller than the large lecture courses often associated with undergraduate study, which might allow for closer connections to be fostered during class time and beyond (Newberry \& Davis, 2008 suggested this was the case in K-12 educational contexts). As Phillips (1979) 
said, graduate study can be described as an intimate relationship between professors and students. "The relationship between professor and student is intimate in every sense of the word. Because they must work closely together, it is customary for student and advisor to spend a great deal of time in each other's company. Disclosures are often made or, at minimum, the individuals learn a great deal about each other; the public release of such knowledge could be mutually damaging. It is not unusual for graduate professors to form long-lasting and very intense personal friendships with their students" (Phillips, 1979, p. 339). Therefore, graduate students were the target population for study two.

\section{Participants}

Participants in Study Two were 196 graduate students. Graduate students were recruited through a variety of sampling methods. The average graduate student in the sample was $27.70(S D=7.50 ;$ Range $=38)$ years old. Of participants, $126(64.29 \%)$ identified as female, $68(34.69 \%)$ identified as male, and $2(1.02 \%)$ identified as gender non-conforming. The majority of the sample was White/Caucasian $(n=158 ; 80.61 \%)$, with additional representation from African-American $(n=4 ; 2.04 \%)$, Asian $(n=5$; $2.55 \%)$, Native American $(n=1 ; 0.51 \%)$, and Latinx $(n=8 ; 4.08 \%)$ ethnicities. Twenty (10.21\%) participants reported multiracial or chose not to report their ethnicity. Of the graduate students, $114(58.2 \%)$ were working on their doctoral degree, $81(41.3 \%)$ were working on Master's degrees, and $1(0.5 \%)$ participant was enrolled in a graduate certificate program. Areas of study varied widely among the graduate student sample, with representation from programs such as accounting, biochemistry, business, clinical psychology, engineering, English, educational psychology, instrumental performance, geology, health sciences, instructional design and technology, law, nursing, pharmacy, 
social work, speech-language pathology, and many others.

The Office of Graduate Education and Life at the host institution was contacted for assistance in sharing the survey with all enrolled graduate students via email in weekly newsletters that were disseminated to all graduate students enrolled at the host institution. Additionally, graduate program coordinators were contacted at the host institution, and were asked to share the study advertisement with graduate students currently enrolled in the graduate coordinator's program.

\section{Procedures}

Procedures in Study 1 were replicated in Study 2, including the same recruitment strategies (see Appendix A for study advertisement), the online questionnaire (see Appendix B for cover letter and Appendix C for questionnaire), and the drawing for five additional $\$ 50$ Amazon gift cards (i.e., gift cards were distributed for both studies, independently).

\section{Measures}

All measures from Study 1 were replicated for Study 2 (see Appendix C for complete list of measures). All measures utilized in Study 2 were also found to be internally consistent: Intimacy $(\alpha=.91, M=3.08, S D=1.33$; Dobranksy \& Frymier, 2004), Closeness $(\alpha=.90, M=3.65, S D=.86$; Vangelisti \& Caughlin, 1997), Communication Satisfaction ( $\alpha=.92, M=5.86, S D=1.02$; Goodboy et al., 2009), Cognitive Learning ( $\alpha=.84, M=3.83, S D=.78$; Frymier \& Houser, 1999), Affect toward the Class ( $\alpha=.83, M=6.22, S D=1.01$; McCroskey, 1994), Affect toward the Instructor $(\alpha=.85, M=6.34, S D=1.04 ;$ McCroskey, 1994), Motivation $(\alpha=.94, M=$ 5.53, $S D=1.12$; Christophel, 1990), and Online Communication Attitude $(\alpha=.86, M=$ 
$5.42, S D=3.24$; Ledbetter 2009a). For data on the amount of time graduate students had known their professors, the frequency of their communication, and the topics covered in their communication, see Descriptive Findings section below.

\section{Summary}

Graduate students took online surveys, asking them to report on either (a) their closest instructor or (b) an instructor they took a course with in the previous semester. Participants were recruited through a network sample, using offices at the host institution and graduate program coordinators at the host institution to begin sampling procedures. Once recruited, participants took the survey online, featuring the core variables of the study. They then were entered into a random drawing for Amazon.com gift cards.

\section{CHAPTER FIVE}

Study 2 Results

\section{Descriptive Findings}

Of the graduate students in the sample of the present study, $107(54.1 \%)$ reported on a close professor and $89(44.9 \%)$ reported on an instructor they had in the previous academic semester. Graduate students used an average of $5.09(S D=2.45)$ modes to communicate with their instructors. When asked what topics they discussed with their instructors outside of the classroom, according to Jaasma and Koper's (2001) typology, 189 students (97\%) reported they discussed course-related topics, 144 students $(72.7 \%)$ used small talk, 139 students (70.2\%) asked for advice, 149 students said they discussed intellectual ideas $(75.3 \%), 40$ students $(20.2 \%)$ reported that they would ask for a favor, 40 students (20.2\%) engaged in self-disclosure with their professor, and 12 students $(6.1 \%)$ provided other topics that came up during their OCC with their professor. Other 
topics covered during OCC included family/personal issues, research, life as a graduate student/tips, the job search, and professional development (the student or the instructor, see Table 8).

Table 8. Study 2 Modality Usage Descriptive Statistics

\begin{tabular}{lccccccc}
\hline \multicolumn{1}{c}{ Mode } & \multicolumn{2}{c}{$\begin{array}{c}\text { Frequency of } \\
\text { Use }\end{array}$} & \multicolumn{2}{c}{$\begin{array}{c}\text { Class } \\
\text { Requirement }\end{array}$} & \multicolumn{2}{c}{$\begin{array}{c}\text { Communication } \\
\text { Initiation }\end{array}$} \\
& $\begin{array}{c}\text { Total \# of } \\
\text { Students }\end{array}$ & $M$ & $S D$ & $\begin{array}{c}\text { \# of } \\
\text { Students }\end{array}$ & $\%$ & $M$ & $S D$ \\
\hline Face-to-Face & $186(94.90 \%)$ & 4.63 & 1.29 & 140 & $71.43 \%$ & 4.96 & 2.15 \\
Email & $195(99.50 \%)$ & 4.71 & 1.01 & 107 & $54.59 \%$ & 5.02 & 2.43 \\
LMS & $104(53.06 \%)$ & 2.54 & 1.81 & 86 & $43.88 \%$ & 7.18 & 3.00 \\
Discussion & $88(44.89 \%)$ & 2.39 & 1.80 & 44 & $22.45 \%$ & 5.78 & 3.02 \\
Boards & & & & & & & \\
Document & $105(53.57 \%)$ & 2.60 & 1.75 & 24 & $12.24 \%$ & 5.63 & 2.78 \\
Sharing Systems & & & & & & & \\
Google & $17(8.67 \%)$ & 1.18 & 0.70 & 2 & $1.02 \%$ & 5.00 & 2.16 \\
Classroom & & & & & & & \\
Phone Calls & $66(68.75 \%)$ & 1.73 & 1.21 & 4 & $2.04 \%$ & 5.26 & 2.39 \\
Video Chat & $36(18.37 \%)$ & 1.43 & 1.05 & 4 & $2.04 \%$ & 5.58 & 2.23 \\
Text Messaging & $67(34.18 \%)$ & 1.97 & 1.54 & 4 & $2.04 \%$ & 4.63 & 2.03 \\
Instant & $15(7.65 \%)$ & 1.22 & 0.87 & 2 & $1.02 \%$ & 4.88 & 1.85 \\
Messaging & & & & & & & \\
Handwritten & $81(41.33 \%)$ & 2.09 & 1.51 & 17 & $8.67 \%$ & 5.97 & 2.82 \\
Social Media & $29(14.80 \%)$ & 1.43 & 1.81 & 1 & $0.51 \%$ & 4.89 & 1.91 \\
Apps & $8(4.08 \%)$ & 1.10 & 0.56 & 1 & $0.51 \%$ & 4.95 & 1.73 \\
Online Gaming & $3(1.53 \%)$ & 1.04 & 0.39 & 0 & $0.00 \%$ & 4.80 & 1.12 \\
\hline
\end{tabular}

Note. Frequency was measured using a 6-point Likert-type scale. Who initiated the communication was measured using a 10-point scale, with a score of 10 indicating the instructor initiated more communication via that channel, a score of 1 indicating the student initiated more communication via that channel, and a score of 5 indicating an equal amount of communication initiation.

\section{Measurement Model}

To test the proposed model (H1, H2, and H3, featured in Figure 1), a structural equation modeling (SEM) approach was used, following the same data analysis techniques used in Study1. Again using maximum-likelihood robust estimation (MLR), the model fit criteria were: a non-significant chi-square; a comparative fit index $(\mathrm{CFI}) \geq$ .95 ; a root mean square error of approximation (RMSEA) $\leq .08$ accompanied by a $90 \%$ 
confidence interval with an upper bound of .10 or less, and a standardized root-meanresidual $(\mathrm{SRMR}) \leq .08(\mathrm{Hu} \&$ Bentler, 1999; Kline, 2016). The CFA for Study 2 yielded the following global fit: Satorra-Bentler $\chi^{2}(1378)=8577.214, p<.001$, MLR Scaling Correction Factor $=1.051, \mathrm{RMSEA}=0.074$ [90\% CI: 0.070, 0.078], CFI $=0.811, \mathrm{SRMR}$ $=0.078$. While the RMSEA and SRMR were within acceptable thresholds, the SatorraBentler chi-square was significant, and the CFI value was lower than the accepted .96 threshold. Therefore, local fit was inspected through the standardized residuals. Standardized residuals ranged from +/- 0.056 to 7.313 . The highest residual was between the fourth item on the motivation scale and the fifth item on the communication satisfaction scale. Modification indices suggested that if these items were to be correlated, the chi-square could be reduced by 11.497 units. However, as done in Study 1, no error terms on items were specified to covary to improve model fit, and so the existing measurement model was retained (see Table 9).

Table 9. Study 2 Measurement Model

\begin{tabular}{lc}
\hline Variable $\quad$ Item & $\begin{array}{c}\text { Factor } \\
\text { Loading }\end{array}$ \\
\hline Intimacy (Dobransky \& Frymier, 2004) & .79 \\
Warm/Cold & .78 \\
Intimate/Not Intimate & .85 \\
Emotionally close/Emotionally distant & .84 \\
Familiar/Unfamiliar & .85 \\
Caring/Not Caring & .75 \\
How close are you to your instructor of [class name]? & .85 \\
How much do you like your instructor of [class name]? & .58 \\
How often do you talk about personal things with your & \\
instructor of [class name]? & .69 \\
How important is your instructor of [class name]'s & \\
opinion to you? & .73 \\
How satisfied are you with your relationship with your & \\
instructor of [class name]? & .86 \\
How much do you enjoy spending time with your &
\end{tabular}


How important is your relationship with your instructor $\quad .76$ of [class name]?

Communication Satisfaction (Goodboy et al., 2009)

My communication with my instructor feels satisfying. $\quad .83$

I dislike talking with my instructor.*

I am not satisfied after talking to my instructor.* $\quad .49$

Talking with my instructor leaves me feeling like I $\quad .83$

accomplished something.

My instructor fulfills my expectations when I talk to $\quad .88$

them.

My conversations with my instructor are worthwhile. $\quad .91$

When I talk to my instructor, the conversations are $\quad .92$

rewarding.

My instructor makes an effort to satisfy the concerns I $\quad .79$ have.

Affect toward Class (McCroskey, 1994)

Bad/Good* $\quad .89$

Valuable/Worthless $\quad .58$

Unfair/Fair* $\quad .82$

Positive/Negative $\quad .72$

Affect toward Instructor (McCroskey, 1994)
Bad/Good*

Valuable/Worthless $\quad .63$

Unfair/Fair* $\quad .83$

Positive/Negative $\quad .78$

Motivation (Christophel, 1990)

Motivated/Unmotivated $\quad .85$

Interested/Uninterested $\quad .86$

Involved/Uninvolved $\quad .80$

Not Stimulated/Stimulated* $\quad .80$

Don't want to study/Want to study* $\quad .73$

Inspired/Uninspired $\quad .81$

Unchallenged/Challenged $* \quad .59$

Uninvigorated/Invigorated ${ }^{*} \quad .81$

Unenthused/Enthused* $\quad .90$

Excited/Not Excited $\quad .78$

Aroused/Not aroused $\quad .41$

Not fascinated/Fascinated $* \quad .82$

Cognitive Learning (Frymier \& Houser, 1999)

I like to talk about what I'm doing in class with friends $\quad .38$

and family.

I explain course content to other students. $\quad .39$

I think about the course content outside the class. $\quad .62$

I see connections between the course content and my $\quad .81$

career goals.

I review the course content. 
I compare the information from this class with other

things I have learned.

I feel I have learned a lot in this class.

Online Communication Attitude (Ledbetter, 2009a)

Online communication is convenient. $\quad .68$

I enjoy communicating online.

I like that it is easy to get ahold of people through online $\quad .77$

communication.

When life gets busy, online communication is a great $\quad .81$

way to communicate efficiently.

Online communication is a stress-free way to get in $\quad .65$

touch with someone.

Online communication is fun.

.59

Note. All factor loadings were significant at the $p<.001$ level. Reverse-coded items are marked with an asterisk.

\section{Hypothesized Model Results}

As in Study 1, a path model approach was conducted using the composite variables outlined above (see Table 10 for a correlation table of all variables used in Study 2).

Table 10. Study 2 Pearson Correlations

\begin{tabular}{llcccccc}
\hline Variable & 2. & 3. & 4. & 5. & 6. & 7. & 8. \\
\hline 1. Closeness & $.760^{* *}$ & $.536^{* *}$ & $.525^{* *}$ & $.653^{* *}$ & $.667^{* *}$ & .001 & $.425^{* *}$ \\
2. Comm. Satisfaction & -- & $.406^{* *}$ & $.634^{* *}$ & $.766^{* *}$ & $.711^{* *}$ & -.004 & $.153^{*}$ \\
3. Cognitive Learning & -- & $.380^{* *}$ & $.327^{* *}$ & $.505^{* *}$ & .022 & $.240^{* *}$ \\
4. Affect toward Class & & & -- & $.755^{* *}$ & $.676^{* *}$ & -.008 & .087 \\
5. Affect toward & & & -- & $.731^{* *}$ & -.029 & .111 \\
Instructor & & & & & -.037 & .118 \\
6. Motivation & & & & -- & .082 \\
7. OCA & & & & & & -- \\
8. \# of Modes & & & & & & & \\
Note. ${ }^{* *}$ Correlation is significant at the $p<.01$ level. * Correlation is significant at the $p<.05$ \\
level.
\end{tabular}

Both closeness $(X)$ and OCA $(W)$ were mean-centered, as done in Study 1. Using maximum likelihood estimation with 10,000 percentile bootstraps, global fit revealed the following model fit statistics: $\chi^{2}(10)=8.07, p=.62$, RMSEA $=0.00$ [90\% CI: 0.00 , 0.07], $\mathrm{CFI}=1.00, \mathrm{SRMR}=0.024$ (see Figure 4 for path estimates). 
Figure 4. Study 2 Hypothesized Model

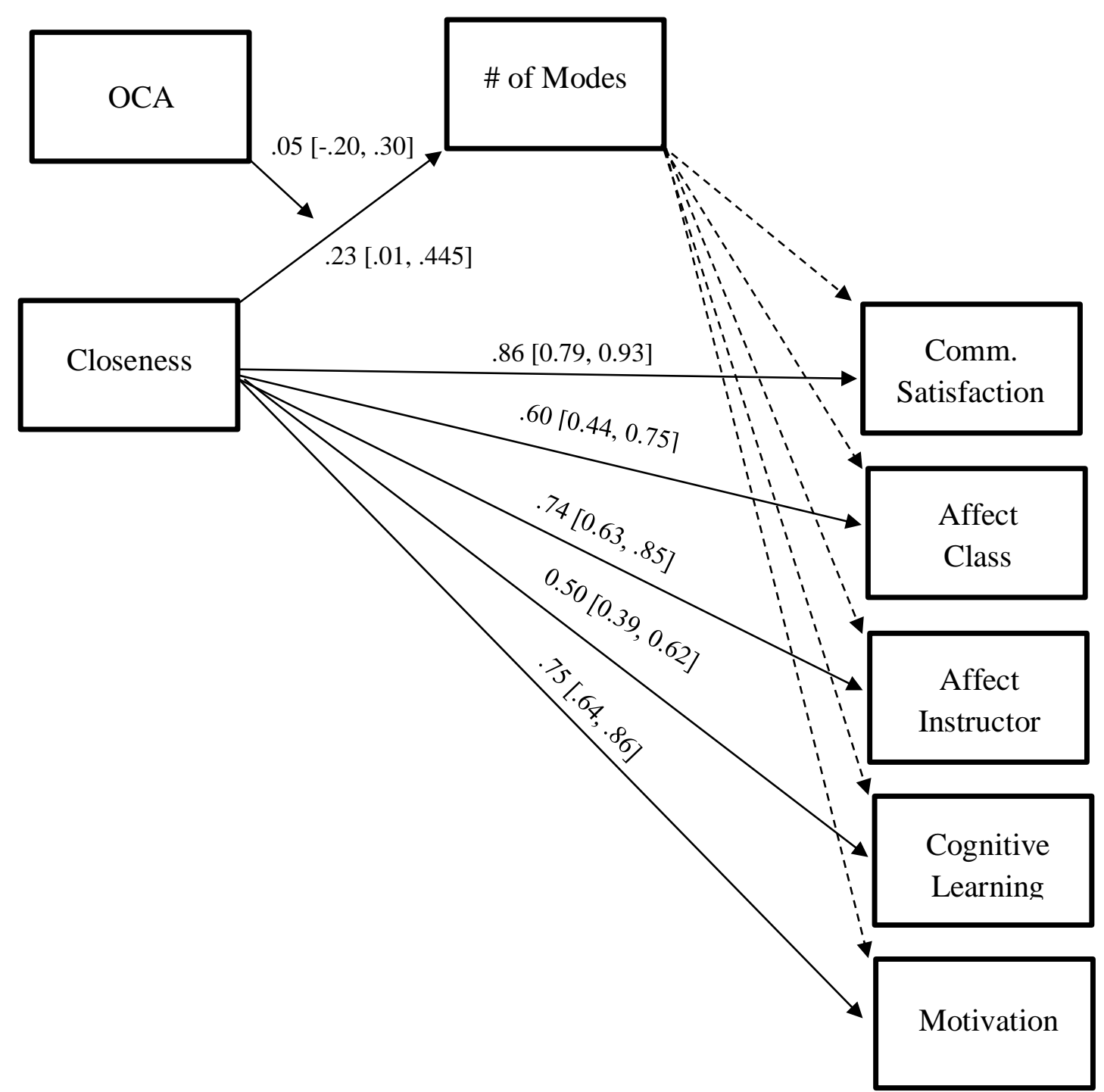

Note. All estimates are standardized, and confidence intervals were generated using 10,000 percentile bootstraps. Confidence intervals excluding zero are shown, while those including zero are featured as dashed paths.

The pattern of results from the hypothesized model in Study 2 suggest that instructor-student closeness had positive direct effects on all classroom outcomes (communication satisfaction, affective and cognitive learning, and student motivation). However, multiplexity (or the number of modes used to communicate) had null effects on 
communication satisfaction, affective learning, and student motivation. Student-instructor closeness had a positive effect on the number of modalities used to communicate, and there was a positive interaction between closeness and online communication attitude on number of mode used for communication.

To test for the presence of moderated mediation, the index of moderated mediation was generated for all five outcomes in the present study. Confidence intervals that excluded zero were interpreted as evidence to suggest the presence of conditional indirect effects (see Table 11). These results convey that there were no conditional indirect effects in the hypothesized model. $\mathrm{H} 1$ predicted that the number of modes used to communicate would increase instructor and student closeness $\left(R^{2}=.061\right)$, and was supported with data from Study 2. H2 predicted that the number of modes used to communicate would positively predict student outcomes. H2 was not supported, as there were null effects for multiplexity on all five of the positive instructional outcomes: communication satisfaction $\left(R^{2}=.320\right)$, affect toward the instructor $\left(R^{2}=.242\right)$, affect toward the course $\left(R^{2}=.239\right)$, cognitive learning $\left(R^{2}=.279\right)$, and motivation $\left(R^{2}=.298\right)$. H3 was not supported in Study 2, as the confidence interval surrounding the interaction effect included zero.

Table 11. Study 2 Conditional Indirect Effects for Hypothesized Model

\begin{tabular}{ccccc}
\hline Index of Moderated Mediation (IMM) & & \multicolumn{3}{c}{ Bootstrapped CI } \\
\hline Conditional Indirect Effects & Effect & $S E$ & LLCI & ULCI \\
\hline Communication Satisfaction $(\mathbf{I M M )}$ & $\mathbf{0 . 0 0 2}$ & $\mathbf{0 . 0 0 5}$ & $\mathbf{- 0 . 0 2 8}$ & $\mathbf{0 . 0 3 9}$ \\
$\theta_{\mathrm{ab} / \mathrm{OCA}}=4.34(-1 S D)$ & -0.005 & 0.008 & -0.019 & 0.014 \\
$\theta_{\mathrm{ab} / \mathrm{OCA}}=5.42(M)$ & -0.027 & 0.009 & -0.046 & -0.010 \\
$\theta_{\mathrm{ab} / \mathrm{OCA}}=6.50(+1 S D)$ & -0.050 & 0.013 & -0.076 & -0.025 \\
Cognitive Learning $(\mathbf{I M M})$ & $\mathbf{0 . 0 0 3}$ & $\mathbf{0 . 0 0 5}$ & $\mathbf{- 0 . 0 1 4}$ & $\mathbf{0 . 0 3 4}$ \\
$\theta_{\mathrm{ab} / \mathrm{OCA}}=4.34(-1 S D)$ & 0.000 & 0.002 & -0.004 & 0.005 \\
$\theta_{\mathrm{ab} / \mathrm{OCA}}=5.42(M)$ & 0.001 & 0.007 & -0.013 & 0.015 \\
$\theta_{\mathrm{ab} / \mathrm{OCA}}=6.50(+1 S D)$ & 0.002 & 0.012 & -0.023 & 0.027
\end{tabular}




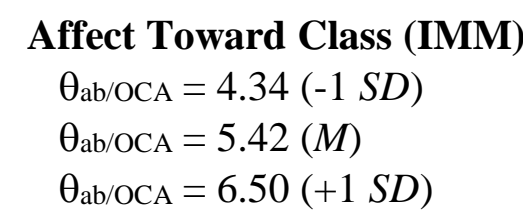

Affect Toward Instructor (IMM)

$\theta_{\mathrm{ab} / \mathrm{OCA}}=4.34(-1 S D)$

$\theta_{\mathrm{ab} / \mathrm{OCA}}=5.42(M)$

$\theta_{\mathrm{ab} / \mathrm{OCA}}=6.50(+1 S D)$

Motivation (IMM)

$\theta_{\mathrm{ab} / \mathrm{OCA}}=4.34(-1 S D)$

$\theta_{\mathrm{ab} / \mathrm{OCA}}=5.42(M)$

$\theta_{\mathrm{ab} / \mathrm{OCA}}=6.50(+1 S D)$

$\begin{array}{rrrr}\mathbf{- 0 . 0 1 9} & \mathbf{0 . 0 0 7} & \mathbf{- 0 . 0 3 3} & \mathbf{0 . 0 1 7} \\ -0.004 & 0.008 & -0.020 & 0.011 \\ -0.024 & 0.012 & -0.050 & -0.005 \\ -0.044 & 0.019 & -0.083 & -0.010 \\ \mathbf{0 . 0 0 1} & \mathbf{0 . 0 0 7} & \mathbf{- 0 . 0 3 2} & \mathbf{0 . 0 3 0} \\ -0.004 & 0.007 & -0.019 & 0.011 \\ -0.023 & 0.011 & -0.049 & -0.005 \\ -0.043 & 0.017 & -0.080 & -0.012 \\ \mathbf{0 . 0 0 0} & \mathbf{0 . 0 0 8} & \mathbf{- 0 . 0 3 6} & \mathbf{0 . 0 2 7} \\ -0.004 & 0.008 & -0.022 & 0.012 \\ -0.026 & 0.012 & -0.054 & -0.006 \\ -0.048 & 0.019 & -0.089 & -0.013\end{array}$

Note. Evidence for conditional indirect effects are indicated by an index of moderated mediation (IMM) whose confidence interval excludes zero. Variables with conditional indirect effects are flagged with an asterisk (*) for ease of interpretation.

\section{Alternative Model Test}

An alternative model test was conducted also using a path model. For the alternative model (as in Study 1), the independent and mediating variable were transposed, so that the number of modes used to communicate (i.e., the multiplexity of communication) would predict student-instructor closeness, which in turn would influence the student outcomes of communication satisfaction, motivation, and affective and cognitive learning. Using maximum likelihood estimation with 10,000 bootstraps, the following global fit was found: $\chi^{2}(10)=11.24, p=.339, \mathrm{RMSEA}=.026$ [90\% CI: 0.00 , 0.09], CFI $=.998, \mathrm{SRMR}=.026$ (see Figure 5 for path estimates). The AIC and BIC statistics were used to compare the alternative model with the hypothesized model. The AIC of the hypothesized model was 2862.78 and the BIC of the hypothesized model was 2975.86. The AIC of the alternative model was 2300.69 and the BIC was 2413.59. Because the BIC was lower by 449.19 units for the alternative model, the alternative model was retained for Study 2 . 
Figure 5. Study 2 Alternative Model

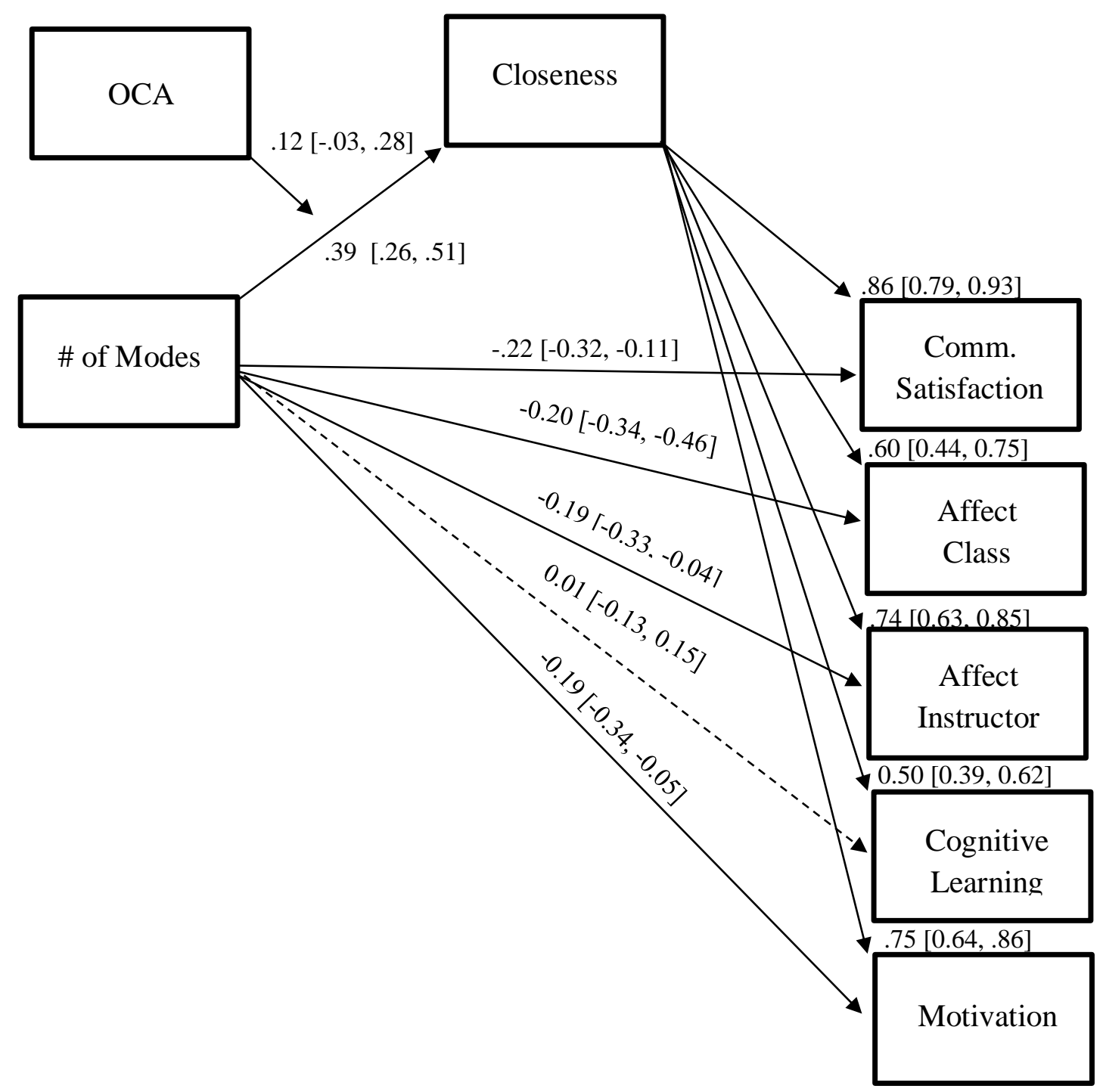

Note. All estimates are standardized, and confidence intervals were generated using 10,000 percentile bootstraps. Confidence intervals excluding zero are shown, while those including zero are featured as dashed paths.

The pattern of results from the alternative model suggest the number of modes used to communicate (multiplexity) does increase perceptions of student-instructor closeness $\left(R^{2}\right.$ $=.165)$, and that closeness leads to positive effects in all five perceptual outcomes: 
communication satisfaction $\left(R^{2}=.618\right)$, affect toward the class $\left(R^{2}=.269\right)$, affect toward the instructor $\left(R^{2}=.465\right)$, cognitive learning $\left(R^{2}=.264\right)$, and motivation $\left(R^{2}=.464\right)$. The results from the alternative model, however, does not provide evidence for conditional indirect effects, as all confidence intervals for the indices of moderated mediation include zero (see Table 12).

Table 12. Study 2 Conditional Indirect Effects for Alternative Model

\begin{tabular}{|c|c|c|c|c|}
\hline \multicolumn{2}{|l|}{ Index of Moderated Mediation (IMM) } & \multicolumn{3}{|c|}{ Bootstrapped CI } \\
\hline Conditional Indirect Effects & Effect & $S E$ & LLCI & ULCI \\
\hline Communication Satisfaction (IMM) & 0.037 & 0.028 & -0.006 & 0.102 \\
\hline$\theta_{\mathrm{ab} / \mathrm{OCA}}=4.34(-1 S D)$ & 0.291 & 0.118 & 0.106 & 0.578 \\
\hline$\theta_{\mathrm{ab} / \mathrm{OCA}}=5.42(M)$ & 0.330 & 0.147 & 0.101 & 0.689 \\
\hline$\theta_{\mathrm{ab} / \mathrm{OCA}}=6.50(+1 S D)$ & 0.370 & 0.176 & 0.095 & 0.801 \\
\hline Cognitive Learning (IMM) & 0.015 & 0.011 & -0.002 & 0.039 \\
\hline$\theta_{\mathrm{ab} / \mathrm{OCA}}=4.34(-1 S D)$ & 0.118 & 0.044 & 0.046 & 0.221 \\
\hline$\theta_{\mathrm{ab} / \mathrm{OCA}}=5.42(M)$ & 0.134 & 0.055 & 0.044 & 0.262 \\
\hline$\theta_{\mathrm{ab} / \mathrm{OCA}}=6.50(+1 S D)$ & 0.150 & 0.066 & 0.042 & 0.305 \\
\hline Affect Toward Class (IMM) & 0.023 & 0.017 & -0.004 & 0.063 \\
\hline$\theta_{\mathrm{ab} / \mathrm{OCA}}=4.34(-1 S D)$ & 0.118 & 0.077 & 0.067 & 0.366 \\
\hline$\theta_{\mathrm{ab} / \mathrm{OCA}}=5.42(M)$ & 0.186 & 0.094 & 0.066 & 0.432 \\
\hline$\theta_{\mathrm{ab} / \mathrm{OCA}}=6.50(+1 S D)$ & 0.211 & 0.112 & 0.062 & 0.501 \\
\hline Affect Toward Instructor (IMM) & 0.032 & 0.026 & -0.005 & 0.097 \\
\hline$\theta_{\mathrm{ab} / \mathrm{OCA}}=4.34(-1 S D)$ & 0.253 & 0.118 & 0.081 & 0.542 \\
\hline$\theta_{\mathrm{ab} / \mathrm{OCA}}=5.42(M)$ & 0.288 & 0.145 & 0.078 & 0.646 \\
\hline$\theta_{\mathrm{ab} / \mathrm{OCA}}=6.50(+1 S D)$ & 0.322 & 0.173 & 0.073 & 0.751 \\
\hline Motivation (IMM) & 0.034 & 0.026 & -0.005 & 0.097 \\
\hline$\theta_{\mathrm{ab} / \mathrm{OCA}}=4.34(-1 S D)$ & 0.270 & 0.117 & 0.092 & 0.552 \\
\hline$\theta_{\mathrm{ab} / \mathrm{OCA}}=5.42(M)$ & 0.306 & 0.144 & 0.089 & 0.655 \\
\hline$\theta_{\mathrm{ab} / \mathrm{OCA}}=6.50(+1 S D)$ & 0.343 & 0.172 & 0.084 & 0.759 \\
\hline
\end{tabular}

Note. Evidence for conditional indirect effects are indicated by an index of moderated mediation (IMM) whose confidence interval excludes zero. Variables with conditional indirect effects are flagged with an asterisk $(*)$ for ease of interpretation.

\section{Summary}

Study 2 found the alternative model to be a stronger fit for the data than the hypothesized model. Results from the graduate student sample suggested that multimodality increased student perceptions of student-instructor closeness, and that 
student-instructor closeness had positive effects on communication satisfaction, cognitive learning, affective learning, and motivation.

\section{CHAPTER 6}

\section{Discussion}

Instructional communication scholars have argued that teaching is both "fundamentally relational and communicative" (Dannels, 2015, p. 17). To further investigate the student-instructor relationship as both relational and communicative, this project sought to test if the effects of multimodal out-of-class communication (OCC) in the student-instructor relationship would mimic the effects of similar communication patterns in other types of relational communication, such as those among organizational members or friendships, through the lens of media multiplexity theory (MMT;

Haythornthwaite, 2005). Results from the two studies conducted for this project supported H1, which predicted that student-instructor tie strength (as operationalized as closeness) would positively predict the number of media channels used for OCC. However, neither study provided support for $\mathrm{H} 2$, which predicted that the number of media channels used for student-instructor OCC would positively predict student (a) communication satisfaction, (b) cognitive learning, (c) affective learning, and (d) motivation. While Study 1 found no results between the number of modes used to communicate and communication satisfaction, cognitive and affective learning, or motivation, Study 2 did find that number of modes used to communicate negatively predicted communication satisfaction, affective learning, and motivation. However, H3, which predicted that online communication attitude will moderate the relationship between tie strength and number of channels used to communicate, was only supported in 
Study 1. Enjoyment of online communication amplified the effects of the number of modes used to communicate on closeness in Study 1. This discussion will revolve around contextualizing these results in light of previous research, discuss the theoretical implications of these findings, and offer future directions for research.

\section{Theoretical Implications}

Broadly, the present set of studies provides support for and extends boundary conditions for two theories: Media Multiplexity Theory (MMT; Haythorthwaite, 2005) and Medium Enjoyment Theory (MET; Taylor et al., 2017). Both studies found that perceived student-instructor closeness positively predicted media multiplexity, suggesting that as perceptions of closeness increased, so did the number of modes used to communicate. This replicates and extends the original work of Haythornthwaite (2005) who found the same pattern of effects to be present in communication among distance learners and among organizational members. However, in both studies, alternative models were tested due to the cross-sectional nature of the data collection. In the case of both studies, the alternative models were stronger fit to the data than were the hypothesized model. The alternative models produced better fit because of the ordering of the variables. In the alternative models, the variable of closeness was specified as the independent (exogenous) variable, and the media multiplexity (operationalized as the number of modes used to communicate) was specified as the mediating variable. This order was not specified the original theory, but past interpersonal research has also found support for this temporal precedence. Haythornthwaite found closeness (tie strength) to positively predict greater modes used to communicate, but subsequent work in interpersonal relationships (i.e., Ledbetter 2009b, Ledbetter \& Mazer, 2014) found that 
frequency of multimodal communication leads to relational interdependence (using interdependence as the operationalization for tie strength in interpersonal relationships). Further, Taylor and Bazarova (2018) spearheaded a longitudinal approach to MMT, and in a study following romantic partners over 6 weeks, they found that there was a significant, positive association between number of media used to communicate and relational closeness. The data from the present set of studies supports these studies and further suggests that the order that these variables naturally occur in may first be the use of increased media to communicate, and second feelings of closeness or interdependence. This order of events is important for future work on MMT, as it can both inform the development of close relationships from a theoretical lens, but it can also aid future researchers in study designs when pursuing tests of MMT, particularly using longitudinal or experimental methods.

Also of import for the extension of MMT are the null direct effects between the number of modes used to communicate between the instructor and the student and the instructional outcomes of interest found in the present studies (except among graduate students, which found some negative direct effects). Taking past research on OCC into consideration, it is clear that while OCC can be used for multiple purposes, it is also conducted through multiple channels. To expand on these findings, the present set of studies considered how all channels used for OCC impact the student holistically. Moreover, previous research had suggested that participating in more OCC results in greater learning and relational outcomes for students (i.e., Pascarella, 1980; Young et al., 2011). Specifically, by combining both functional and relational OCC, students experience greater satisfaction with communication (Aylor \& Oppliger, 2003), greater 
cognitive and affective learning (Goldman et al., 2016), and greater motivation (Jaasma \& Koper, 1999; Kerssen-Griep et al., 2003). However, contrary to the predictions of the present studies, the findings from extent OCC research did not replicate when additively considering channels used for student-instructor OCC. Instead, the greater modes used to communicate with one's instructors had no effect on their communication satisfaction, cognitive and affective learning, and motivation. However, despite the presence of null direct effects, the overall model suggests that MMT indirectly impacts these positive classroom outcomes. Broadly, this null (and negative in Study 2) direct effect can be explained by several emerging lines of research in the field of instructional communication, surrounding trends that suggest students approach communication with their instructor with a task orientation (rather than a relational orientation), as well as structural issues and power dynamics imposed within the student-instructor relationship.

There is mounting evidence to suggest that the instructor-student relational context may not be perceived as relational in nature, at least from the student perspective. For example, Clark-Gordon et al. (2018) found that when instructors incorporated interpersonal cues into feedback messages, such as the use of emojis or photos, students did not perceive the instructor as more humanized or caring. Likely, students perceived these messages as the functional, or related to the tasks at hand, and not as relational messages. In a study that examined instructors use of virtual office hours, where instructors offered instant messaging (IM) conversations to their students, results suggested that participants in classes that offered virtual office hours reported higher levels of satisfaction with office hours than students in classes that offered only traditional face-to-face office hours (Li, Finley, Pitts, \& Guo, 2011). Also revealed, 
however, was that students' report that they prefer the asynchronicity of email and IM communication, but the use of virtual office hours was not statistically different from their use of traditional office hours (Li et al., 2011). Distant relationships (as compared to interpersonally close relationships) also engage in and prefer asynchronous communication (i.e., Jiang \& Hancock, 2013), so perhaps the closeness scores reported above are unsurprising. Further, in an experiment that examined student perceptions of a professor's Twitter profile, personal tweets (as compared to professional messages) were not seen as more caring or socially attractive (Clark-Gordon \& Goodboy, 2018).

Students' perceptions of professor's Twitter use, even when relational in nature, is not perceived by students as such. This pattern of results suggests that despite instructor attempts to connect with students through interpersonal cues and messages, students do not perceive them as interpersonal in nature.

While interpersonal communication broadly studies the social interaction between people (i.e., Berger, 2010), there are several distinctions between an interpersonal relationship between a student and an instructor and other types of interpersonal relationships. The most complicated aspects of understanding the student-instructor relationship as interpersonal are tied up in the nonvoluntary nature of the relationship, as well as the power distance it creates. Students may or may not have the opportunity to choose which instructor to enroll in a course with, forcing students to have some connection with an instructor that may not be of their own choosing. Further, instructors are responsible for classroom management, including course policies. Course policies, such as technology policies, can be a distinguishing factor in the student-instructor relationship from other types of interpersonal relationships. For example, establishing 
clear technology policies has been associated with increased perceptions of instructor credibility, but unclear technology policies have been shown to decrease credibility perceptions (Finn \& Ledbetter, 2013). Finn and Ledbetter (2014) found that students desire not only clarity (as found by Finn \& Ledbetter, 2013), but also choices involving technology in the classroom, insofar as students were more sensitive to policies that regulated laptops/tablets than cell phones in the classroom, and want choices for academic technology use. However, students in Finn and Ledbetter's (2014) study reported understanding of social regulation of technology use in the classroom, but desired freedom for academic uses of technology. The negotiation of the power distance and various course policies, such as technology policies, further separates the instructorstudent from other types of interpersonal relationships.

Additionally, and likely with important implications for MMT, is that instructors may instate mandatory modes of communication both in- and out-of-class. The results of the present set of studies suggested that, largely, both undergraduate and graduate students communicate with their instructors face-to-face, or via email or learning management systems (such as Blackboard). Of undergraduate students in Study 1, 72.3\% said face-to-face communication was mandatory, $44.88 \%$ said that email communication was mandatory, and $39.9 \%$ said that communication in a learning management system was mandatory. Similar percentages of graduate students in Study 2 emerged, $71.43 \%$ reported that face-to-face communication was mandatory, 54.59\% reported that email was mandatory, and $43.88 \%$ reported that learning management systems were mandatory. These data demonstrate that students are not able to choose all of the modes they communicate with their professors, or may have limited choices due to instructor 
policies. Because of mandatory use of certain media, as dictated by the instructor, students may not have a choice in the matter of how many modes they use to communicate with their instructor. For example, in the present set of studies, students were asked on a 10-point scale who initiated communication (the student or the instructor), with a score of 1 indicating communication was initiated solely by the student, a score of 5 indicated that modes were initiated equally, and a score of 10 indicated that the instructor solely initiated communication via that channel. Using onesample t-tests against the 5 midpoint of the scale, data suggested that of the mandatory modes used for communication, face-to-face communication was initiated equally by both parties: $t(239)=-1.88, p=.06$, Cohen's $d=1.76,(M=4.68, S D=2.67)$ for undergraduate students, and $t(179)=-.243, p=.81$, Cohen's $d=2.31,(M=4.96, S D=$ 2.15) for graduate students. However, for email communication, the undergraduate students $(t(238)=-3.062, p=.002$, Cohen's $d=1.43, M=4.39, S D=3.06)$ were more likely to initiate, and there was no significant different in initiation of emails for graduate students $(t(174)=.093, p=.93$, Cohen's $d=2.07, M=5.02, S D=2.43$. For communication through learning management systems (such as Blackboard) the instructors of undergraduate students $(t(172)=9.376, p<.001$, Cohen's $d=2.32, M=$ $7.22, S D=3.11)$ and graduate students $(t(122)=8.06, p<.001$, Cohen's $d=2.39, M=$ $7.18, S D=3.00)$ were more likely to initiate. Extent research also supports these claims. Tatum, Olson, and Frey (2018) found that discouraging cell phone policies in classrooms caused students to feel diminished autonomy, and in accordance with psychological reactance theory, students restored their autonomy by disregarding the cell phone policies (noncompliance) as well as other uncivil classroom behaviors, such as dissenting the 
instructor. A qualitative study on student-faculty interactions illustrated key factors that can both deter and facilitate student-faculty interactions (Cotten \& Wilson, 2006). Results from Cotten and Wilson's (2006) focus group study with undergraduate students suggest that student time, interest, insecurity, and awareness all affect interactions with college faculty. Specifically, they cited that student insecurity and lack of awareness about the purpose of office hours or other available communication channels were the biggest deterrent for faculty-student interaction. For these reasons, there must be distinctions between other types of interpersonal relationships and those that are specific to the student-instructor context. While students and instructors may meet Granovetter's (1973) four criteria that determine tie strength (time, emotional intensity, intimacy, and reciprocal services), it does not necessarily make the relationship "interpersonal" in the way that is commonly thought of by scholars. As Berger (2010) notes, "much of everyday social interaction is organized around recurring goals that arise in the course of everyday living. The routines associated with everyday family and work interactions, and with daily transactions in business and commerce, encourage the development of communication routines in order to reach these recurring goals effectively and efficiently" (p. 6). Perhaps, students and instructors do not need that many modes of communication to reach their respective goals effectively and efficiently, so integrating more of them could be counter to their goals both in and out of the classroom.

Study 1 also provide support for MET in the context of instructional communication. The data suggests that for undergraduate students who have greater enjoyment of online communication, they will find more ways to communicate with their instructor when they feel close with them. However, this finding was null for graduate 
students, so the data from Study 2 suggests that the effects of closeness on media multiplexity does not change in strength or in direction based on the graduate students' online communication attitude. Overall, when extending MMT to the context of instructional communication, the present studies suggest that there is an overall positive indirect effect of closeness on positive instructional outcomes, through the number of modes used to communicate. Although the direct effects of modes on the positive classroom outcomes (communication satisfaction, cognitive and affective learning, and motivation) were null (and even negative in Study 2's alternative model) in both studies, fostering greater closeness between students and instructors might be one way to overcome these limitations in situations where instructors need to communicate with students through many modes.

\section{Practical Implications}

The results from the present set of studies also provide practical implications for instructors relating to their communication with students. The pattern of results suggest that greater student-instructor closeness leads a to a greater number of modes used to communicate (supporting MMT), but using more modes to communicate decreases, or has no effect on, students' perceived communication satisfaction, cognitive and affective learning, and motivation. These results suggest that while fostering a close connection between students and instructors is beneficial, reaching out to students in a wide variety of ways is not seen as helpful. Broadly, students have a "diet" that makes up their use of communication technologies and social media (e.g., Bowman, Westerman \& Claus, 2012), where they socially interact with others on a daily basis. It could be that, when students receive information that they perceive as task-based (i.e., relating to 
coursework), they experience reactance or deleterious effects, because those media are largely used by the student for fun or social purposes.

Media richness theory (MRT) provides a theoretical lens for understanding why increasing the number of modes used to communicate might not enhance a student's perceived learning or motivation in a given course. According to Daft and Lengel (1984), certain channels of mediated communication carry more social information than others, because of the number of cues available to message senders and receivers. These cues may aid in interpretation of the message or resolve ambiguity. Daft and Lengel argue, particularly in organizations, that managers must carefully choose communication channels based on the task. For example, an email message may carry very little additional social information, but a video call may allow for much more social information, due to affordances such as the visibility of nonverbal cues and synchronous feedback. Because communication between instructors and students can be more taskoriented (rather than socially-oriented), students may only attend to the cues they see as necessary for this focal task (i.e., coursework). Adding extra forms of communication, then, may have been disliked by students because the extra modes of communication were seen as superfluous to the task at hand (assignments or other classroom activities). MRT would refer to this concept as task equivocality, wherein richer nonverbal cues are needed only when there is some level of ambiguity or uncertainty related to a message (Daft \& Lengel, 1984). In the case of student-instructor communication, the student may not need any more cues from additional beyond what is required for a course - in the present set of studies, these modes were face-to-face, email, and through their learning management system (ex., Blackboard). 
Additionally, the descriptive findings from the present set of studies offer interesting insights for instructors of both graduate and undergraduate students. For both undergraduate and graduate students, the most commonly used channels for communication between instructors and students were face-to-face, email, and learning management systems. Additionally, for graduate students document sharing systems were very commonly used to communicate with their instructors. Instructors and students initiated communication via these channels evenly, except for in the case of communication through learning management systems, where communication was largely initiated by instructors. Of undergraduate students, $72.3 \%$ reported that face-toface communication was required for the course they reported on, $44.3 \%$ reported that email was required, and $39.9 \%$ reported that using a learning management system was required. On a six-point frequency scale, undergraduate students reported using face-toface communication the most often $(M=4.44, S D=1.31)$, email was the second most used mode to communicate $(M=4.06, S D=1.19)$, and learning management systems were used the third most frequently $(M=2.61, S D=1.51)$. For graduate students, $71.43 \%$ reported that face-to-face communication was required, $54.59 \%$ reported that email communication was required, and $43.88 \%$ reported the communication through learning management systems were a class requirement. Only $12.24 \%$ of graduate students reported that document sharing systems (ex., Google Docs) were required for the course they reported on. Graduate students used email to communicate the most frequently $(M=$ $4.71, S D=1.01)$, followed by face-to-face communication $(M=4.63, S D=1.29)$, and learning management system communication $(M=2.54, S D=1.81)$. Largely, these descriptive results suggest that undergraduate and graduate instructors communicate in 
the same ways with their students, but communication may happen more frequently with graduate students than with undergraduate students, despite not being a class requirement. For example, graduate students reported using email for the most communication with their instructors, but only about half of graduate students reported that email communication was a class requirement (54.59\%).

\section{Limitations and Future Directions}

A limitation of the present set of studies was the approach taken to studying student-instructor relationships. The present studies asked undergraduate and graduate students to report on a close or a recent instructor to attempt to capture a greater range of closeness in student-instructor relationships. However, the project did not actually capture the granularity of different types of student-instructor relationships. The students in the present samples, both undergraduate and graduate, were not particularly close with their instructors, as previously discussed. To further examine MMT in a closer studentinstructor context, different types of student-instructor relationships need to be examined, as these different types of relationships might provide for more variance in relational closeness. For example, a graduate student's relationship with their thesis or dissertation chair may vary vastly from an instructor they have had for one course. For undergraduate students, factors such as faculty advising and class size would likely play a large role in how close a student and instructor are able to come over the course of a semester or over the course of their undergraduate study. Future research could take a more nuanced approach to understanding types of instructor-student relationships, rather than regarding them as homogenous.

A second limitation of the present study was its cross-sectional design. While this 
limitation was combatted, in part, by testing alternative models, further research should consider longitudinal designs to introduce the ability to account for time order in the relational development. By incorporating a longitudinal study design, perhaps over the course of a semester, researchers could track changes in modality usage and communication habits. In the context of the instructor-student relationship, not only would testing MMT longitudinally help to establish temporal precedence, it would also provide researchers with richer data to describe the points of inflection throughout the semester where relational development occurs or changes, as well as potentially to consider time itself as a variable when considering Granovetter's (1973) conceptualization of time as a core component of tie closeness. Future research should continue this line of work, using longitudinal designs could elicit a more nuanced understanding of the facets integral to multimodal communication in mixed-mode relationships.

The present set of studies also examined general attitudes toward enjoyment of online communication, which may be another limitation. Enjoyment of online communication was found to moderate the relationship between closeness and the number of modes used to communicate in both Study 1 and Study 2. Broadly, this suggests that at a trait level, those students who enjoy online communication more will find more channels to communicate with their instructors. However, according to Medium Enjoyment Theory (MET; Taylor et al., 2017), this actually may matter at the mode- or channel-level. Taylor et al. (2017) argue for MET, where individuals' attitudes shape their use of a medium, and their desire to self-disclose or socially connect are conceptualized as different forms of enjoyment. In combining both technologically and 
socially oriented theories, they frame media use as an individuals' desire for enjoyable media experiences, which can be limited by the potentially competing desire for communication goal achievement. Future research integrating online communication attitude with MMT should not consider only general attitude towards online communication, but instead account for attitudes held toward each specific modality of interest (such as measuring enjoyment of face-to-face communication, email communication, learning management system communication, etc. used in the present studies). By having attitudinal and frequency questions about each mode used in a mixedmode relationship, more information could be revealed about this pattern of effects. The present study only measured one dimension of online communication attitudes, enjoyment, as it is thought to be the most proximal to understanding channel choice (according to MET; Taylor et al., 2017). However, future research could utilize measures of attitudes towards self-disclosure or social connection (additional dimensions of the MOCA; Ledbetter, 2009a) to further understand perceptions towards channel usage. Additionally, other (less positive) attitudes toward online communication could serve as further moderators, such as computer-mediated communication anxiety (CMCA). CMCA is conceptualized as the level of fear or apprehension that an individual experiences regarding the anticipated or actual use of information technology for communication (Brown, Fuller, \& Vician, 2004). CMC anxiety is often examined in distance education settings (e.g., Hauser, Paul, \& Bradley, 2012) and from the learner's perspective (e.g., Wombacher, Harris, Buckner, Frisby, \& Limperos, 2017). Research on CMCA could be extended into the context of MMT, and could be an additional moderator to explain why students may shy away from using more modes to communicate in the instructor-student 
relationship.

Lastly, a limitation of this research was that both samples were collected from one institution. The decision to only collect data at one institution was made to hold the culture of the university constant across the samples. The host institution is a large, midAtlantic, research-intensive university. The "culture" at the host institution may, ostensibly, differ from small, liberal arts colleges or Ivy League universities. However, despite sampling from one university, no measures of campus culture were used to test this claim in the present set of studies. Future studies should consider campus culture not only in study design, but also consider recruiting at diverse universities.

\section{Conclusion}

The present set of studies examined media multiplexity theory (MMT; Haythornthwaite, 2005) in the context of student-instructor out-of-class communication (OCC). It was predicted that student-instructor closeness would predict the number of media used for OCC, and subsequently, the number of modes used for OCC would predict positive classroom outcomes, including communication satisfaction, cognitive and affective learning, and motivation. It was also predicted that the effect between closeness and number of modes used for OCC would be contingent upon the student's attitude toward online communication, so if they did not hold positive attitudes towards online communication, it would suppress the amount of modes used to communicate outside the classroom.

For undergraduate students, it was found that the number of media used to communicate with one's instructor indirectly impacted their communication satisfaction, affective and cognitive learning, and motivation, through their feelings of the closeness 
with their instructor, the opposite direction of the hypothesized model. This effect was strengthened for those students who had greater enjoyment of online communication. Study 2 found the alternative model to be a stronger fit for the data than the hypothesized model. Results from Study 2 suggested that multimodality increased student perceptions of student-instructor closeness, and that student-instructor closeness had positive effects on communication satisfaction, cognitive learning, affective learning, and motivation.

This discussion highlighted these results as areas of alignment and departure from previous work on MMT. The alternative model testing done in both Study 1 and Study 2 suggested that media multiplexity lead to greater student-instructor closeness, which in turn resulted in greater communication satisfaction, cognitive and affective learning, and motivation in the student. However, online communication attitude only amplified this effect for undergraduate students in Study 1, but not for graduate students in Study 2. Clarifications for this finding was offered, and particularly due to the nature of the instructor-student relationship, citing the potential of task-related communication as well as the policies and goals of the instructor as having the potential to shape the way the student-instructor relationship could develop. In summary, MMT was supported by the present studies, and important conclusions on the nature of the student-instructor relationship, and the subsequent effects of their communication patterns can be drawn. 


\section{References}

Anderson, L. E., \& Carta-Falsa, J. (2002). Factors that make faculty and student relationships effective. College Teaching, 50, 134-138. doi:10.1080/87567550209595894

Asparouhov, T., \& Muthén, B. (2018). SRMR in Mplus. Retreived from: http://www. statmodel. com/download/SRMR2. pdf.

Aylor, B., \& Oppliger, P. (2003). Out-of-class communication and student perceptions of instructor humor orientation and socio-communicative style. Communication Education, 52, 122-134. doi:10.1080/0363452032000085090

Bandalos, D. L. (2018). Measurement theory and applications for social sciences. New York, NY: Guilford.

Baym, N. K., \& Ledbetter, A. (2009). Tunes that bind? Predicting friendship strength in a music-based social network. Information, Communication \& Society, 12, 408427. doi:10.1080/13691180802635430

Berger, C. (2010). Interpersonal Communication. In W. Donsbach (Ed.) The International Encyclopedia of Communication (1 ${ }^{\text {st }}$ ed.). Hoboken, NJ: John Wiley \& Sons, Ltd. doi:10.1002/9781405186407.wbieci077

Bippus, A. M., Kearney, P., Plax, T. G., \& Brooks, C. F. (2003). Teacher access and mentoring abilities: Predicting the outcome value of extra class communication. Journal of Applied Communication Research, 31, 260-275. doi:10.1080/00909880305379

Bishop, J. L., \& Verleger, M. A. (2013, June). The flipped classroom: A survey of the research. In ASEE national conference proceedings, Atlanta, GA. 
Bowman, N. D., Westerman, D. K., \& Claus, C. J. (2012). How demanding is social media: Understanding social media diets as a function of perceived costs and benefits - A rational actor perspective. Computers in Human Behavior, 28, 22982305. doi:10.1016/j.chb.2012.06.037

Brown, S. A., Fuller, R. M., \& Vician, C. (2004). Who's afraid of the virtual world? Anxiety and computer mediated communication. Journal of the Association for Information Systems, 5, 79-107. doi:10.17705/1jais.00046

Catt, S., Miller, D., \& Schallenkamp, K. (2007). You are the key: Communicate for learning effectiveness. Education, 127, 369-377.

Caughlin, J. P., \& Sharabi, L. L. (2013). A communicative interdependence perspective of close relationships: The connections between mediated and unmediated interactions matter. Journal of Communication, 63, 873-893. doi:10.1111/jcom.12046

Chickering, A. W., \& Reisser, L. (1993) Education and identity (2 ${ }^{\text {nd }}$ Ed.). San Francisco, CA: Jossey-Bass.

Christophel, D. M. (1990). The relationships among teacher immediacy behaviors, student motivation and learning. Communication Education, 39, 323-340. doi:10.1080/03634529009378813

Clark-Gordon, C. V., Bowman, N. D., Hadden, A. A., \& Frisby, B. N. (2019). College instructors and the digital red pen: An exploration of factors influencing the adoption and non-adoption of digital written feedback technologies. Computers \& Education, 128, 414-426. doi:10.1016/j.compedu.2018.10.002

Clark-Gordon, C. V., Bowman, N. D., Watts, E. R, Banks, J., \& Knight, J. M. (2018). 
"As good as your word": Face-threat mitigation and the use of nonverbal cues on students' perceptions of digital instructor feedback. Communication Education, 67, 206-225. doi:10.1080/03634523.2018.1428759

Clark-Gordon, C. V., \& Goodboy, A. K. (2018, November). Instructor self-disclosure and third-party generated warrants: Student perceptions of professor social media use. Paper presented at the 104th National Communication Association, Salt Lake City, Utah.

Claus, C. J., Booth-Butterfield, M., \& Chory, R. M. (2012). The relationship between instructor misbehaviors and student antisocial behavioral alteration techniques: The roles of instructor attractiveness, humor, and relational closeness. Communication Education, 61, 161-183. doi:10.1080/03634523.2011.647922

Cotten, S. R., \& Wilson, B. (2006). Student-faculty interactions: Dynamics and determinants. Higher Education, 51, 487-519. doi:10.1007/s10734-004-1705-4

Dannels, D. P. (2015). 8 essential questions teachers ask: A guidebook for communication with students. New York, NY: Oxford University Press.

de Kleijn, R. A., Meijer, P. C., Pilot, A., \& Brekelmans, M. (2014). The relation between feedback perceptions and the supervisor-student relationship in master's thesis projects. Teaching in Higher Education, 19, 336-349.

doi:10.1080/13562517.2013.860109

Dobransky, N. D., \& Frymier, A. B. (2004). Developing teacher-student relationships through out of class communication. Communication Quarterly, 52, 211-223. doi:10.1080/01463370409370193

Faranda, W. T. (2015). The effects of instructor service performance, immediacy, and 
trust on student-faculty out-of-class communication. Marketing Education Review, 25, 83-97. doi:10.1080/10528008.2015.1029853

Finn, A. N., \& Ledbetter, A. M. (2013). Teacher power mediates the effects of technology policies on teacher credibility. Communication Education, 62, 26-47. doi:10.1080/03634523.2012.725132

Finn, A. N., \& Ledbetter, A. M. (2014). Teacher verbal aggressiveness and credibility mediate the relationship between teacher technology policies and perceived student learning. Communication Education, 63, 210-234. doi:10.1080/03634523.2014.919009

Frisby, B. N., \& Martin, M. M. (2010). Instructor-student and student-student rapport in the classroom. Communication Education, 59, 146-164. doi:10.1080/03634520903564362

Frymier, A. B., \& Houser, M. L. (1999). The revised learning indicators scale. Communication Studies, 50, 1-12. doi:10.1080/10510979909388466

Frymier, A. B., \& Houser, M. L. (2000). The teacher-student relationship as an interpersonal relationship. Communication Education, 49, 207-219. doi:10.1080/03634520009379209

Fusani, D. S. (1994). "Extra-class" communication: Frequency, immediacy, selfdisclosure, and satisfaction in student-faculty interaction outside the classroom. Journal of Applied Communication Research, 22, 232-255. doi:10.1080/00909889409365400

Gerbing, D. W., \& Anderson, J. C. (1984). On the meaning of within-factor correlated measurement errors. Journal of Consumer Research, 11, 572-580. 
Goldman, Z. W., Goodboy, A. K., \& Bolkan, S. (2016). A meta-analytical review of students' out-of-class communication and learning effects. Communication Quarterly, 64, 476-493. doi:10.1080/01463373.2015.1103293

Goodboy, A. K., Martin, M. M., \& Bolkan, S. (2009). The development and validation of the student communication satisfaction scale. Communication Education, 58, 372396. doi:10.1080/03634520902755441

Granovetter, M. (1973). The strength of weak ties. American Journal of Sociology, 78, 1360-1380. doi:10.1086/225469

Hattie, J. (2009). Visible learning: A synthesis of over 800 meta-analyses relating to achievement. New York, NY: Routledge.

Hauser, R., Paul, R., Bradley, J. (2012). Computer self-efficacy, anxiety, and learning in online versus face to face medium. Journal of Information Technology Education: Research, 11, 141-154. doi:10.28945/1633

Hayes, A. F. (2018). Introduction to Mediation, Moderation, and Conditional Process Analysis: A Regression-Based Approach (2 $2^{\text {nd }}$ ed.). New York, New York: Guilford.

Haythornthwaite, C. (2005). Social networks and internet connectivity effects. Information, Community \& Society, 8, 125-147. doi:10.1080/13691180500146185

Herold, B. (2016, February). Technology in education: An overview. Education Week. http://www.edweek.org/ew/issues/technology-in-education/index.html

Hu, L. T., \& Bentler, P. M. (1999). Cutoff criteria for fit indexes in covariance structure analysis: Conventional criteria versus new alternatives. Structural Equation Modeling: A Multidisciplinary Journal, 6, 1-55. doi:10.1080/10705519909540118 
Jaasma, M. A., \& Koper, R. J. (2001). Talk to me: An examination of the content of outof-class interaction between students and faculty. Paper presented at the 51st Annual Meeting of the International Communication Association, Washington, DC.

Jiang, L. C., \& Hancock, J. T. (2013). Absence makes the communication grow fonder: Geographic separation, interpersonal media, and intimacy in dating relationships. Journal of Communication, 63, 556-577. doi:10.1111/jcom.12029

Jones, S. R. \& Abes, E. S. (2013). Identity development of college students: Advancing frameworks for multiple dimensions of identity. San Francisco, CA: Jossey-Bass.

Jorgenson, J. (1992). Communication, rapport, and the interview: A social perspective. Communication Theory, 2, 148-156. doi:10.1111/j.1468-2885.1992.tb00034.x

Jowett, S. (2003). When the "honeymoon" is over: A case study of a coach-athlete dyad in crisis. The Sport Psychologist, 17, 444-460. doi:10.1123/tsp.17.4.444

Jowett, S. (2007). Interdependence analysis and the $3+1 \mathrm{Cs}$ in the coach-athlete relationship. In S. Jowette \& D. Lavallee (Eds.), Social psychology in sport (pp. 15-27). Champaign, IL, US: Human Kinetics.

Junco, R. (2015). Student class standing, Facebook use, and academic performance. Journal of Applied Developmental Psychology, 36, 18-29. doi:10.1016/j.appdev.2014.11.001

Kerssen-Griep, J., Hess, J. A., \& Trees, A. R. (2003). Sustaining the desire to learn: Dimensions of perceived instructional facework related to student involvement and motivation to learn. Western Journal of Communication, 67, 357-381. doi:10.1080/10570310309374779 
Kline, R. B. (2016). Principles and practice of structural equation modeling ( $4^{\text {th }} \mathrm{ed}$.). New York, NY: Guilford Press.

Knapp, J. L., \& Martin, M. M. (2002, April). Out-of-class communication: The development and testing of a measure. Paper presented at the Eastern Communication Association Convention, New York City, New York.

Kuh, G. D. (1995). The other curriculum: Out-of-class experiences associated with student learning and personal development. The Journal of Higher Education, 66, 123-155. doi:10.1080/00221546.1995.11774770

Kuznekoff, J. H., \& Titsworth, S. (2013). The impact of mobile phone usage on student learning. Communication Education, 62, 233-252. doi:10.1080/03634523.2013.767917

Lasswell, H. D. (1948). The structure and function of communication in society. The Communication of Ideas, 37, 215-228. doi:10.1515/9781400878642-007

Lee, J., \& Jablin, F. M. (1995). Maintenance communication in superior-subordinate work relationships. Human Communication Research, 22, 220-257. doi:10.1111/j.1468-2958.1995.tb00367.x

Ledbetter, A. M. (2009a). Measuring online communication attitude: Instrument development and validation. Communication Monographs, 76, 463-486. doi:10.1080/03637750903300262

Ledbetter, A. M. (2009b). Patterns of media use and multiplexity: Associations with sex, geographic distance and friendship interdependence. New Media \& Society, 11, 1187-1208. doi:10.1177/1461444809342057

Ledbetter, A. M., \& Kuznekoff, J. H. (2012). More than a game: Friendship relational 
maintenance and attitudes toward Xbox LIVE communication. Communication Research, 39, 269-290. doi:10.1177/0093650210397042

Ledbetter, A. M., \& Mazer, J. P. (2014). Do online communication attitudes mitigate the association between Facebook use and relational interdependence? An extension of media multiplexity theory. New Media \& Society, 16, 806-822.

doi:10.1177/1461444813495159

Li, L., Finley, J., Pitts, J., \& Guo, R. (2011). Which is a better choice for student-faculty interaction: synchronous or asynchronous communication? Journal of Technology Research, 2, 1-12.

Marsden, P. V., \& Campbell, K. E. (1984). Measuring tie strength. Social Forces, 63, 482-501. doi:10.1093/sf/63.2.482

Marsden, P. V., \& Campbell, K. E. (2012). Reflections on conceptualizing and measuring tie strength. Social Forces, 91, 17-23. doi:10.1093/sf/sos112

Mazer, J. P. (2017). Students' discrete emotional responses in the classroom: unraveling relationships with interest and engagement. Communication Research Reports, 34, 359-367. doi:10.1080/08824096.2017.1365233

Mazer, J. P., McKenna-Buchanan, T. P., Quinlan, M. M., \& Titsworth, S. (2014). The dark side of emotion in the classroom: Emotional processes as mediators of teacher communication behaviors and student negative emotions. Communication Education, 63, 149-168. doi:10.1080/03634523.2014.904047

Miczo, N., Mariani, T., \& Donahue, C. (2011). The strength of strong ties: Media multiplexity, communication motives, and the maintenance of geographically close friendships. Communication Reports, 24, 12-24. 
doi:10.1080/08934215.2011.555322

McCroskey, J. C. (1992). An introduction to communication in the classroom. Edina, MN: Burgess.

McCroskey, J. C. (1994). Assessment of affect toward communication and affect toward instruction in communication. In S. Morreale \& M. Brooks (Eds.), 1994 SCA summer conference proceedings and prepared remarks: Assessing college student competence in speech communication (pp. 56-71). Annandale, VA: Speech Communication Association.

Mohr, T. M. (2013). Iclickers and student performance. International Review of Economics Education, 14, 16-23. doi:10.1016/j.iree.2013.10.006

Mottet, T. P., Frymier, A. B., \& Beebe, S. A. (2006). Theorizing about instructional communication. In T. P. Mottet, V. P. Richmond, \& J. C. McCroskey (Eds.), Handbook of instructional communication: Rhetorical and relational perspectives (pp. 255-282). Boston, MA: Allyn \& Bacon.

Myers, S. A., Baker, J. P., Barone, H., Kromka, S. M., \& Pitts, S. (2017). Using rhetorical/relational goal theory to examine college students' impressions of their instructors. Communication Research Reports, 35, 1-10. doi:10.1080/08824096.2017.1406848

Myers, S. A., Goldman, Z. W., Atkinson, J., Ball, H., Carton, S. T., Tindage, M. F., \& Anderson, A. O. (2016). Student civility in the college classroom: Exploring student use and effects of classroom citizenship behavior. Communication Education, 65, 64-82. doi:10.1080/03634523.2015.1061197

Myers, S. A., Martin, M. M., \& Knapp, J. L. (2005). Perceived instructor in-class 
communicative behaviors as a predictor of student participation in out of class communication. Communication Quarterly, 53, 437-450.

doi:10.1080/01463370500102046

Nadler, M. K., \& Nadler, L. B. (2000). Out-of-class communication between faculty and students: A faculty perspective. Communication Studies, 51, 176-188. doi:10.1080/10510970009388517

Newberry, M., \& Davis, H. A. (2008). The role of elementary teachers' conceptions of closeness to students on their differential behaviour in the classroom. Teaching and Teacher Education, 24, 1965-1985. doi:10.1016/j.tate.2008.02.015

Pascarella, E. T. (1980). Student-faculty informal contact and college outcomes. Review of Educational Research, 50, 545-595. doi:10.3102/00346543050004545

Phillips, G. M. (1979). The peculiar intimacy of graduate study: A conservative view. Communication Education, 28, 339-345. doi:10.1080/03634527909378376

Privitera, G. J. (2015). Research methods for the behavioral sciences. Thousand Oaks, CA: Sage.

Ruppel, E. K., \& Burke, T. J. (2014). Complementary channel use and the role of social competence. Journal of Computer-Mediated Communication, 20, 37-51. doi:10.1111/jcc4.12091

Ruppel, E. K., Burke, T. J., \& Cherney, M. R. (2018). Channel complementarity and multiplexity in long-distance friends' patterns of communication technology use. New Media \& Society, 20, 1564-1579. doi:10.1177/1461444817699995

Scott, C. R., \& Timmerman, C. E. (2005). Relating computer, communication, and computer-mediated communication apprehensions to new communication 
technology use in the workplace. Communication Research, 32, 683-725. doi:10.1177/0093650205281054

Sharabi, L. L., \& Caughlin, J. P. (2017). What predicts first date success? A longitudinal study of modality switching in online dating. Personal Relationships, 24, 370391. doi:10.1111/pere.12188

Tatum, N. T., Olson, M. K., \& Frey, T. K. (2018). Noncompliance and dissent with cell phone policies: a psychological reactance theoretical perspective. Communication Education, 67, 226-244. doi:10.1080/03634523.2017.1417615

Taylor, S. H., \& Bazarova N. (2018). Revisiting media multiplexity: A longitudinal analysis of media use in romantic relationships. Journal of Communication, 68, 1104-1126. doi:10.1093/joc/jqt055

Taylor, S. H., Ledbetter, A. M., \& Mazer, J. P. (2017). Initial specification of empirical test of media enjoyment theory. Communication Research. Advance online publication. doi:10.1177/0093650217741029

Terenzini, P. T., Pascarella, E. T., \& Blimling, G. S. (1996). Students' out-of-class experiences and their influence on learning and cognitive development: A literature review. Journal of College Student Development, 40, 610-623. doi:10.1007/bf01680039

Titsworth, S., McKenna, T. P., Mazer, J. P., \& Quinlan, M. M. (2013). The bright side of emotion in the classroom: Do teachers' behaviors predict students' enjoyment, hope, and pride? Communication Education, 62, 191-209. doi:10.1080/03634523.2014.904047

Titsworth, S., Quinlan, M. M., \& Mazer, J. P. (2010). Emotion in teaching and learning: 
Development and validation of the classroom emotions scale. Communication Education, 59, 431-452. doi:10.1080/03634521003746156

Vanelisti, A. L., \& Caughlin, J. P. (1997). Revealing family secrets: The influence of topic, function, and relationships. Journal of Social and Personal Relationships, 14, 679-705. doi:10.1177/0265407597145006

Walther, J. B. (1992). Interpersonal effects in computer-mediated interaction: A relational perspective. Communication Research, 19, 52-90.

doi:10.1177/009365092019001003

Walther, J. B., \& Parks, M. R. (2002). Cues filtered out, cues filtered in: Computermediated communication and relationships. In M. L. Knapp \& J. A. Daly (Eds.), Handbook of Interpersonal Communication (3rd ed., pp. 529-563). Thousand Oaks, CA: Sage.

Williams, K. D., \& Frymier, A. B. (2007). The relationship between student educational orientation and motives for out-of-class communication. Communication Research Reports, 24, 249-256. doi:10.1080/08824090701446625

Wood, J. T. (2002). Interpersonal communication: Everyday encounters (3rd ed.). Belmont, CA: Wadsworth.

Wombacher, K. A., Harris, C. J., Buckner, M. M., Frisby, B., \& Limperos, A. M. (2017). The effects of computer-mediated communication anxiety on student perceptions of instructor behaviors, perceived learning, and quiz performance. Communication Education, 66, 299-312. doi:10.1080/03634523.2015.1221511

Wubbels, T., \& Brekelmans, M. (2005). Two decades of research on teacher-student relationships in class. International Journal of Educational Research, 43, 6-24. 
doi:10.1016/j.ijer.2006.03.003

Xu, S., Wang, Z. J., \& David, P. (2016). Media multitasking and well-being of university students. Computers in Human Behavior, 55, 242-250. doi:10.1016/j.chb.2015.08.040

Young, S., Kelsey, D., \& Lancaster, A. (2011). Predicted outcome value of e-mail communication: Factors that foster professional relational development between students and teachers. Communication Education, 60, 371-388. doi:10.1080/03634523.2011.563388 


\section{Appendix A.}

Study Advertisement

\section{Research Study on Student Perceptions of Communication with their Professors}

If you are a current undergraduate or graduate student and over the age of 18, you are eligible to participate in WVU IRB-acknowledged research on student perceptions of their communication with their professors (Protocol \#1811362946). Participants will be entered in a drawing to win $\$ 50$ Amazon Gift Cards for their participation. Participation is completely voluntary. This study will take approximately 20 minutes to complete, and is being conducted by Dr. Nicholas Bowman and Cathlin Clark-Gordon in WVU's Department of Communication Studies. Please contact Cathlin Clark-Gordon at cvc0003@mix.wvu.edu or 304-293-3434 with any questions.

If you're interested in participating, please click here to access the survey: [link here] 


\section{Appendix B.}

Cover Letter

This cover letter is a request for you to take part in a survey designed to study undergraduate and graduate students' perceptions of their communication with their professors. This project is being conducted by Principal Investigator, Dr. Nicholas Bowman, and Co-Investigator, Cathlin Clark-Gordon, in the Department of Communication Studies at West Virginia University.

This online, anonymous survey will take approximately 20 minutes to complete. Your participation is greatly appreciated. We will not be able to identify who you are or how you've responded. To participate in this study, you must be at least 18 years of age. The survey must be completed on a desktop or laptop computer, not a mobile device. After completion of the survey, you will be redirected to a separate link to be entered into a drawing for \$50 Amazon gift cards. Entrance in the drawing for the gift cards is optional, and the information provided for the drawing cannot be traced back to the answers that you provided in the survey.

Your involvement in this project will be kept anonymous. Please complete the questionnaire independently and be sure to read the instructions carefully and answer honestly. There is no right or wrong answer. Participation in this study is voluntary. You may skip certain questions if you want and you may stop completing the questionnaire at any time without fear of penalty. Your actual performance in this study or your refusal to participate or withdrawal from this study will in no way affect your class standing, grades, job status, or status in any athletic or other activity associated with West Virginia University. 
There are no known risks associated with participation in this study. If you would like more information about this research project, feel free to contact Co-Investigator Cathlin Clark-Gordon at cvc0003@mix.wvu.edu. This study has been acknowledged by West Virginia University's Institutional Review Board, and is on file as Protocol \#1811362946. Thank you for your participation.

Sincerely,

\author{
Cathlin Clark-Gordon \\ Co-Investigator \\ cvc0003@mix.wvu.edu
}

\author{
Nicholas Bowman \\ Principal Investigator \\ nicholas.bowman@mail.wvu.edu
}




\section{Appendix C.}

Measures for Survey Instrument

\section{Introductory Questions (Open-Ended)}

EITHER: Thinking back on your [undergraduate/graduate] education so far, what professor or instructor have you felt the closest to?

OR: Think back on one course you completed during the Fall 2018 semester. The following questions will ask you about the instructor of this course, so please identify this course in the questions below.

(For privacy, we ask that instead of providing their name, you provide the name of a course they have taught below. We will use this response in future questions, so be sure to answer carefully and truthfully.)

Name of course:

What format was the course [piped text course name] taught in?
A. Face-to-Face
B. Online
C. Hybrid

How many courses have you taken with this professor?

If more than one, what were the names of the other courses they taught?

Describe a favorite topic covered by this [piped text] professor in class:

\section{Tie Strength}

How long have you known your [piped text for course name] professor personally? (in months):

In an average week, how often do you communicate with [piped text] professor?

Based on the following adjective pair, how close would you say you feel to [piped text] professor? (The closer a number is to the item/adjective, the more you feel that way.)

Distant 12345678910 Close 
What topics do you discuss with [piped text] professor? Please check all that apply:

Course-related

Self-disclosure

Small talk

Advice

Intellectual ideas

Favor requests

Other:

\section{Closeness (Vangelisti \& Caughlin, 1997)}

Thinking back on your relationship with [piped text] instructor, please rate below your degree of closeness with that instructor. Response options are listed below, and range from 1 for not at all to 5 for a great deal. There is neither a right nor wrong answer.

\begin{tabular}{|ccccc|}
\hline Not at all & A little & Somewhat & Much & A great deal \\
1 & 2 & 3 & 4 & 5 \\
\hline
\end{tabular}

_ How close are you to your professor?

How much do you like your professor?

How often do you talk about personal things with your professor?

How important is your professor's opinion to you?

How satisfied are you with your relationship with your professor?

How much do you enjoy spending time with your professor?

How important is your relationship is your relationship with your professor?

Intimacy (Dobransky \& Frymier, 2004)

Please indicate below your feelings towards [piped text] professor. The closer a number 
is to the item/adjective, the more you feel that way.

Intimate 1234567 Not intimate

Emotionally close 1234567 Emotionally distant

Familiar 1234567 Unfamiliar

Warm 1234567 Cold

Caring 1234567 Not caring

\section{Modes used to communicate with professor:}

Listed below are examples of ways students may communicate with their instructors.

Thinking back on your [piped text] instructor, please select the frequency of your communication with them via the channels listed below.

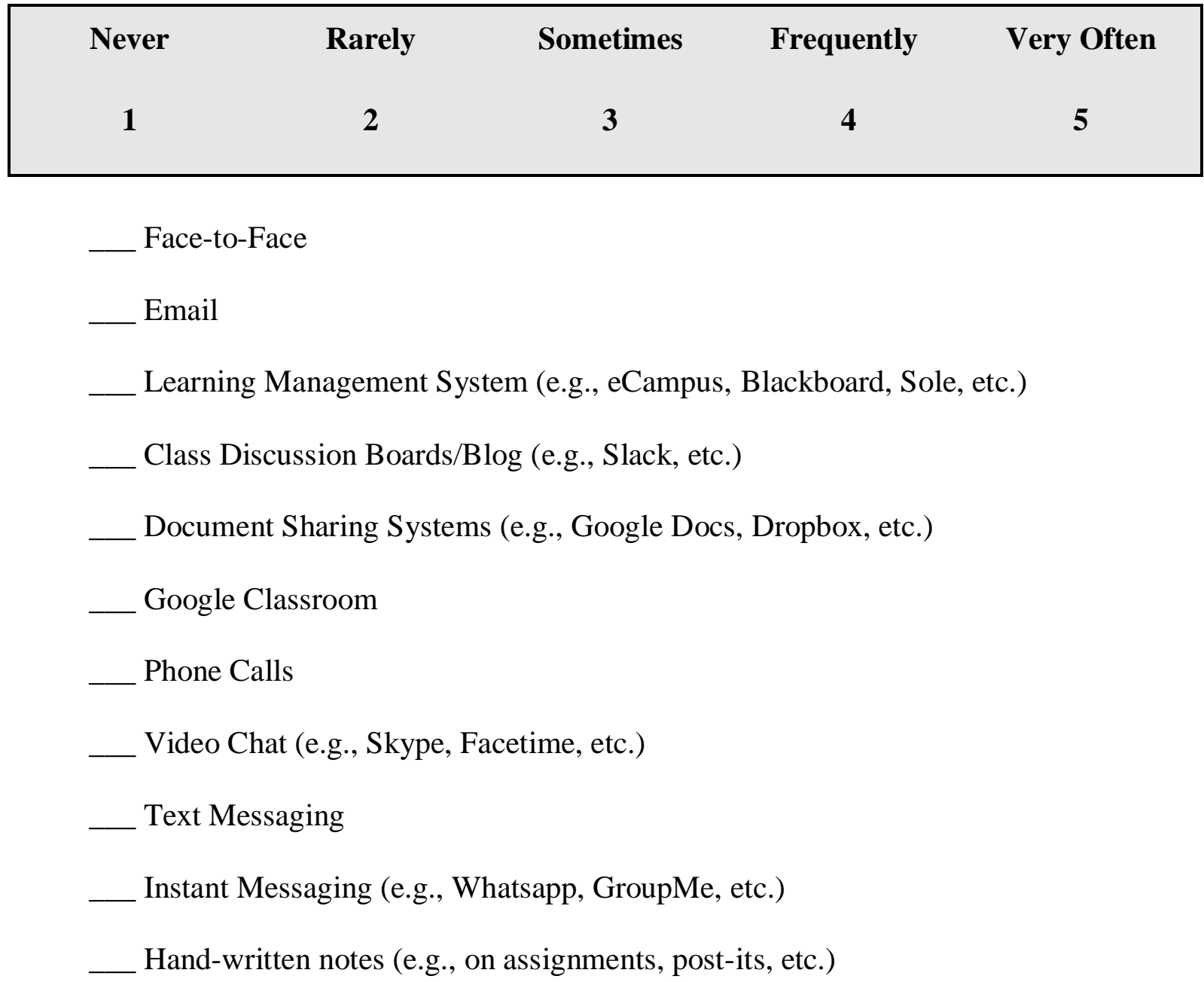


Social Media (e.g., Facebook, LinkedIn, Twitter, Instragram, Snapchat, etc.)

Other Apps (e.g., Remind App, etc.)

_ Online Gaming (e.g., World of Warcraft)

Other 1:

Other 2:

Other 3:

We noticed that you said you communicated with your instructor Face-to-Face. Please select below the contexts in which you communicate with your instructor in Face-to-Face interactions:

_ Office Hours

_ Before/After Class

__ Off-campus meeting (i.e., at a coffee shop, etc.)

__ Running into each other (i.e., on campus or another public location)

_ Social Events

Other:

Below you will see the list of channels you selected previously. Which of the channels you selected were a class requirement? (i.e., communication was mandatory through these channels for your course)

Who initiated the communication via each of these channels you've selected?

\section{Communication Satisfaction (Goodboy, Martin, \& Bolkan, 2009)}

Thinking back on your conversations with [piped text] instructor, please rate below your degree of satisfaction with that communication. Response options are listed below, and range from 1 for strongly disagree to 5 for strongly agree. There is neither a right nor wrong answer.

\begin{tabular}{|ccccc|}
\hline $\begin{array}{c}\text { Strongly } \\
\text { Disagree }\end{array}$ & Disagree & Neutral & Agree & $\begin{array}{c}\text { Strongly } \\
\text { Agree }\end{array}$ \\
1 & 2 & 3 & 4 & 5 \\
\hline
\end{tabular}


My communication with my teacher feels satisfying

I dislike talking with my teacher*

_ I am not satisfied after talking to my teacher*

Talking with my teacher leaves me feeling like I accomplished something

My teacher fulfills my expectations when I talk to him/her

My conversations with my teacher are worthwhile

When I talk to my teacher, the conversations are rewarding

My teacher makes an effort to satisfy the concerns I have

\section{Revised Learning Indicators (Frymier \& Houser, 1999)}

Below is a list of common student behaviors relating to their coursework. Please indicate how often you do each behavior stated below, based on your [piped text] course.

Response options are listed below, and range from 1 for never to 5 for very often. There is neither a right nor wrong answer.

\begin{tabular}{|ccccc|}
\hline Never & Rarely & Sometimes & Frequently & Very Often \\
1 & 2 & 3 & 4 & 5 \\
\hline
\end{tabular}

I like to talk about what I'm doing in this class with friends and family.

I explain course content to other students.

I think about the course content outside the class.

I I see connections between the course content and my career goals.

I review the course content.

I compare the information from this class with other things I have learned.

_ I feel I have learned a lot in this class.

\section{Instructional Affect Assessment Instrument (IAAI; McCroskey, 1994)}

Please indicate below your feelings towards [piped text] professor. The closer a number is to the item/adjective, the more you feel that way. 


\title{
Affect toward content measure
}

I feel the class content is:

Bad 1234567 Good

Valuable 1234567 Worthless*

Unfair 1234567 Fair

Positive 1234567 Negative* $^{*}$

\section{Affect toward instructor measure}

Overall, the instructor I have in the class is:

\author{
Bad 1234567 Good
}

Valuable 1234567 Worthless*

Unfair 1234567 Fair

Positive 1234567 Negative*

State Motivation (Christophel, 1990)

These items are concerned with how you feel about the class you take with [piped text professor]. Please circle the number toward either word which best represents your feelings. Note that in some cases the most positive score is " 1 " while in other cases it is “7”.

Motivated 1234567 Unmotivated*

Interested 1234567 Uninterested*

Involved 1234567 Uninvolved*

Not stimulated 1234567 Stimulated

Don't want to study 1234567 Want to study

Inspired 1234567 Uninspired*

Unchallenged 1234567 Challenged 
Uninvigorated 1234567 Invigorated

Unenthused 1234567 Enthused

Excited 1234567 Not Excited*

Aroused 1234567 Not Aroused*

Not fascinated 1234567 Fascinated

\section{Ledbetter (2009a) Online Communication Attitude - Enjoyment/Ease}

Below are statements that describe individuals' attitude toward online communication. Please indicate the extent to which you agree with the following statements. Response options are listed below, and range from 1 for strongly disagree to 5 for strongly agree. There is neither a right nor wrong answer.

\begin{tabular}{|ccccc|}
\hline $\begin{array}{c}\text { Strongly } \\
\text { Disagree }\end{array}$ & Disagree & Neutral & Agree & $\begin{array}{c}\text { Strongly } \\
\text { Agree }\end{array}$ \\
1 & 2 & 3 & 4 & 5 \\
\hline
\end{tabular}

Online communication is convenient

__ I enjoy communicating online

_ I like that it is easy to get ahold of people through online communication When life gets busy, online communication is a great way to communicate

efficiently

_ Online communication is a stress-free way to get in touch with someone

Online communication is fun

\section{Other Questions/Demographics}

Do you intend to (or are you required to) take a course in the future with the [piped text] professor?

Do you share any writing or data collection responsibilities with the [piped text] 
professor?

Have you or do you intend to co-author manuscripts or publications together with [piped text] professor?

Are you enrolled in a class with [piped text] professor currently?

What is your age?

What is your gender identity?

Which ethnicity do you identify as?

What is your year in school?

First-year

Sophomore

Junior

Senior

Graduate Student

Degree Sought:

Certificate Program

Associate's Degree (A.A.T., A.A., etc.)

Bachelor's Degree (B.A., B.S., etc.)

Master's Degree (M.A., M.B.A., M.F.A., etc)

Doctoral Degree (Ph.D., J.D., M.D., etc.)

What is your major or concentration area of study? 